Research Article

\title{
Numerical Simulation on Carbonation Depth of Concrete Structures considering Time- and Temperature-Dependent Carbonation Process
}

\author{
Jianxin Peng, ${ }^{1}$ Huang Tang $\mathbb{D}^{2},{ }^{2}$ Jianren Zhang, ${ }^{3}$ and Steve C. S. Cai ${ }^{4}$ \\ ${ }^{1}$ School of Civil Engineering, Changsha University of Science and Technology, Changsha, Hunan 410114, China \\ ${ }^{2}$ School of Civil Engineering, Hunan City University, Yiyang, Hunan 413000, China \\ ${ }^{3}$ School of Civil Engineering and Architecture, Changsha University of Science and Technology, Changsha, Hunan 410114, China \\ ${ }^{4}$ Department of Civil and Environmental Engineering, Louisiana State University, Baton Rouge, LA, USA
}

Correspondence should be addressed to Huang Tang; tanghuang_123@163.com

Received 24 March 2018; Accepted 4 July 2018; Published 26 July 2018

Academic Editor: Antonio Boccaccio

Copyright (C) 2018 Jianxin Peng et al. This is an open access article distributed under the Creative Commons Attribution License, which permits unrestricted use, distribution, and reproduction in any medium, provided the original work is properly cited.

In order to further understand the carbonation process of concrete structures, the time- and temperature-dependent diffusion process of $\mathrm{CO}_{2}$ in concrete is simulated based on the law of the $\mathrm{CO}_{2}$ mass conservation, and a two-dimensional mass transfer equation is established for the $\mathrm{CO}_{2}$ diffusion in concrete. The concrete block is discretized into triangular elements, and the $\mathrm{CO}_{2}$ concentrations at different positions are calculated based on finite element method. A computational algorithm is programed through the Matlab platform. The time- and temperature-dependent property and difference of the $\mathrm{CO}_{2}$ concentration at different positions of the structure are considered in the proposed model. Then, an accelerated carbonation experiment is carried out using concrete blocks with different mix proportions to investigate the influence of the water-cement ratio and temperature on the concrete carbonation. The experimental results effectively verify the correctness of the finite element model, and the proposed finite element method reasonably simulates the concrete carbonation through calculating the carbonation in practical engineering compared with other methods in references. An experimental-numerical correlation has been performed. The ratio of carbonation depth at the corner of the concrete members to the other positions is about 1.35 . The carbonation depth is increased about 1.9 times when the temperature changes from $20^{\circ} \mathrm{C}$ to $40^{\circ} \mathrm{C}$.

\section{Introduction}

$\mathrm{CO}_{2}$ concentration is an important factor affecting carbonation in the atmospheric environment. When the $\mathrm{CO}_{2}$ in the air permeates into concrete, the acid-base neutralization reaction happens between the $\mathrm{CO}_{2}$ and the alkaline materials, which leads to the decrease of the concrete alkalinity and the change of chemical composition. When the carbonation front reaches the surface of steel bars, the passivation film on the surface of steel rebar will be destroyed, and then, the corrosion of steel rebars occurs. Overtime, along with the increase of the corrosion products, it is well recognized that the volume of corrosion product is $3 \sim 8$ times larger than that of the steel material. This will result in cover cracking and even spalling and also lead to a reduction of the structural load carrying capacity. These phenomena affect the working performance and durability of concrete structures.

With the development of global economy and the sharp increase of population, the $\mathrm{CO}_{2}$ concentration also increases rapidly. Before the second industrial revolution, the $\mathrm{CO}_{2}$ concentration was about from $265 \mathrm{ppm}$ to $290 \mathrm{ppm}$ in the global atmosphere [1], was about $365 \mathrm{ppm}$ in 2000 [2] $\left(1 \mathrm{ppm}=0.00188 \times 10^{-3} \mathrm{~kg} / \mathrm{m}^{3}\right)$, and reached $400 \mathrm{ppm}$ in 2015, which broke the historical extreme. According to the prediction of International Panel on Climate Change (IPCC), the $\mathrm{CO}_{2}$ concentration will exceed $1000 \mathrm{ppm}$ by 2100 [2]. The $\mathrm{CO}_{2}$ concentrations under various different emission strategies are demonstrated in Figure $1(\mathrm{~A} 1 \mathrm{~F} 1, \mathrm{~B} 1$, and Best mitigation) [3]. A1F1 describes a world of very 


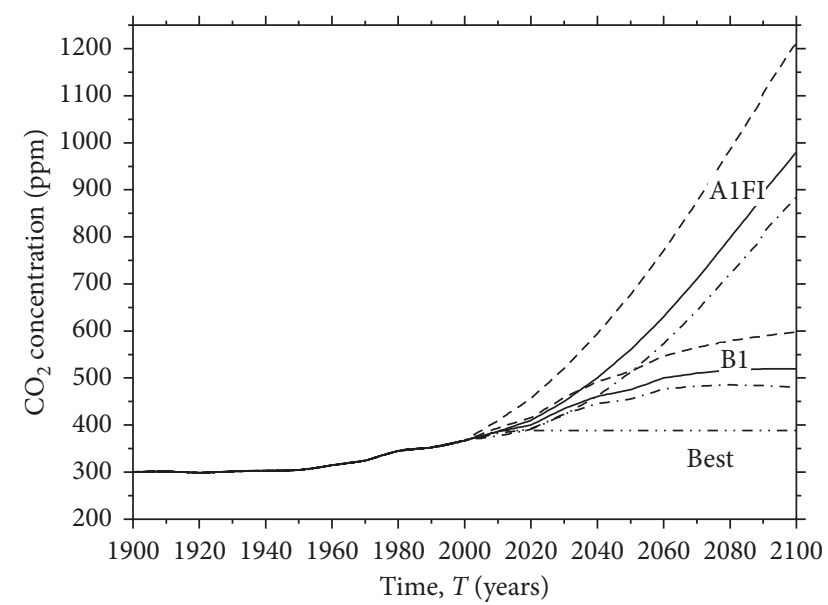

$$
\begin{aligned}
& \text { - - - Upper bounds } \\
& \text {... Lower bounds _.... Best mitigation }
\end{aligned}
$$

Figure 1: Time-dependent change of atmospheric $\mathrm{CO}_{2}$ concentration.

rapid economic growth, a global population that peaks in midcentury, and rapid introduction of new and more efficient technologies that remain fossil intensive, and this is the worst $\mathrm{CO}_{2}$ emission scenario. B1 describes a world with intermediate population and economic growth, emphasizing local solutions to economic, social, and environmental sustainability, and this is the lowest $\mathrm{CO}_{2}$ emission scenario. Best mitigation describes that the $\mathrm{CO}_{2}$ concentration is kept stable at 2010 levels $(386 \mathrm{ppm})$ due to stabilization and reduction of $\mathrm{CO}_{2}$ emissions. The climate change leads to the increase of $\mathrm{CO}_{2}$ concentration, which accelerates the carbonation process of concrete structures, and it is seriously harmful to the structural durability and safety. In present experimental and theoretical studies, the effects of the $\mathrm{CO}_{2}$ concentration on the carbonation of concrete have already been explored by Visser [4], Cui et al. [5], and Castellote et al. [6]; however, the above scholars do not consider the time-dependent character of the $\mathrm{CO}_{2}$ concentration, which will affect the precision of the prediction of the carbonation depth, so it is necessary to consider the time-dependent character of $\mathrm{CO}_{2}$ concentration resulting from climate change when investigating the carbonation progress.

The greenhouse effect has become globalization problem in recent years. According to the prediction of atmospheric temperature from China's National Meteorological Center, the change of temperature in the Beijing district is shown in Figure 2. The average value, lower value and upper value of temperature are presented in Figure 2. Jianxin et al. [7] stated that the diffusion coefficient of concrete carbonation will improve with the increase of temperature, so the temperature change should be considered when predicting the carbonation progress. However, in existing researches [811], the carbonation progress rarely considers the change of temperature. This leads to underestimate concrete carbonation behavior. Therefore, the influence of the temperature change on the carbonation progress should be considered in theoretical and experimental analysis.

Except the $\mathrm{CO}_{2}$ concentration and temperature, the effects of other environmental factors and the concrete

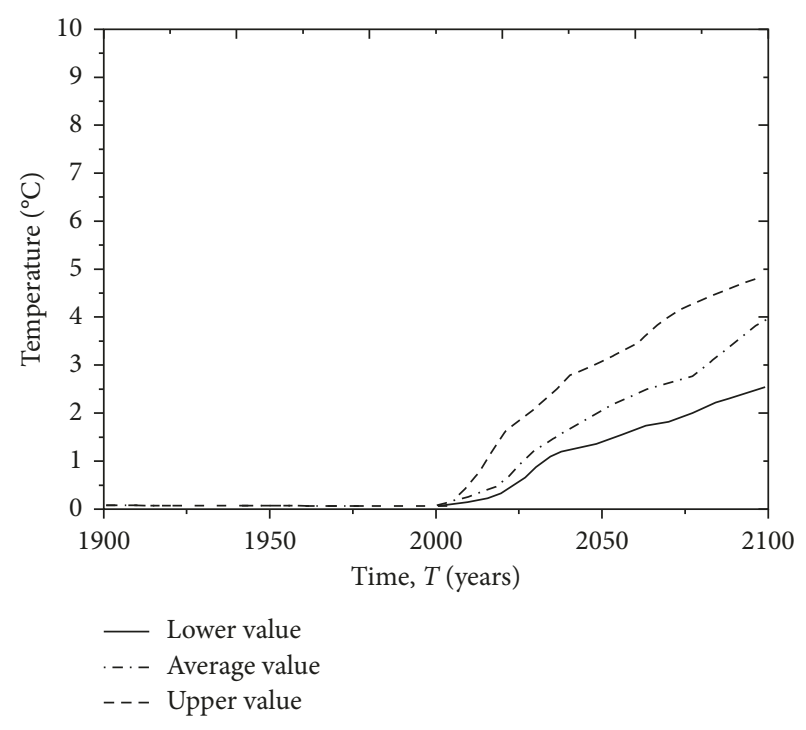

FIgURE 2: Time-dependent temperature change.

material compositions on concrete carbonation have been investigated in-depth in existing researches. The environmental factor includes relative humidity [11-14], and the compositions include water-cement ratio [15], various supplementary cementing materials [16-18], aggregates $[19,20]$, and mix proportions [21, 22]. In these studies, there are few researches about the carbonation situation on the carbonation surface. However, the carbonation degree at the different place on the carbonation face is different, which is meaningful for the research of spatial reliability [23], so it is necessary to carry out the related research.

In recent years, with the rapid development of computer science, many scholars have made numerical simulations of concrete carbonation. Saetta et al. [24, 25] proposed a model to simulate all the phenomena based on carbonation process considering the multidimensional transport of moisture, heat, and carbon dioxide through concrete and taking in account the reduction of the porosity due to carbonation. Burkan Isgor and Razaqpur [10] built a nonlinear finite element approach for tracing the spatial and temporal advancement of the carbonation front in concrete structures with and without cracks. However, the above two models do not consider the time- and temperature-independence of the carbonation coefficient. Saetta et al. [11, 12] established the differential equation of the carbonation process considering the factors such as water, $\mathrm{CO}_{2}$ diffusion, and the variation of temperature and applied to practical engineering for predicting the carbonation depth of a prestressed RC beam, while the detail numerical simulation progress was not carried out for the control equation of the carbonation reflection. Peter et al. [26] proposed the system of reaction-diffusion equations independent of the space dimension, while their numerical simulations only deal with the situations of one-dimensional diffusion. Wang et al. [27] developed the numerical simulation model of the concrete carbonation and determined the value range of the factors of the $\mathrm{CO}_{2}$ diffusion coefficient and the reaction rate of carbonation. However, only two factors were considered in the model, and the model was realized by 
the secondary development of software. As a result, its applicability and versatility were limited. Zha et al. [28] proposed a mathematical model to simulate the physicalchemical coupling process of supercritical carbonation in cement-based materials. This model took into account the rate of chemical reaction, mass conservation for gas-liquid two-phase flow, diffusion and dispersion of $\mathrm{CO}_{2}$ in water, energy conservation for porous medium, and the solubility of $\mathrm{CO}_{2}$ in water, while this model did not consider the influence of the time and temperature variation.

Based on the existing carbonation test and numerical simulation, this research firstly builds a finite element model to predict the carbonation depth considering the time $(t)$ and temperature $(T)$ dependent carbonation diffusion coefficient and carbonation position difference for concrete structures. An experiment is also carried out to investigate the influence of multiple factors such as water-cement ratio, temperature, humidity, and $\mathrm{CO}_{2}$ concentration on the concrete carbonation. The accuracy of the finite element model is also validated by the experimental results and the practical measuring value in engineering.

\section{Numerical Simulation of the Concrete Carbonation considering Time and Temperature Effects}

2.1. Mass Transfer Diffusion Equation of $\mathrm{CO}_{2}$ in Concrete. Carbonation is a series of physical and chemical reactions between acid gases such as $\mathrm{CO}_{2}$ and hydration products of the concrete. The acid gas enters the concrete through pores in concrete. In order to obtain more accurate prediction values of the carbonation depth, it is necessary to simulate the real diffusion process of $\mathrm{CO}_{2}$ in concrete and establish the related mass transfer equation to obtain the value of $\mathrm{CO}_{2}$ mass concentration in concrete.

A control body (microunit with a constant volume) was selected as the research object in the structure. The microunit is cuboid. The side length of the microunit was assumed as $d x$, $d y$, and $d z$, respectively. According to the principle of mass conservation, a balance equation for $\mathrm{CO}_{2}$ gas is

Rate of cumulative $\mathrm{CO}_{2}$ in mass

$$
\begin{aligned}
= & \text { rate of } \mathrm{CO}_{2} \text { influx in mass } \\
& - \text { rate of } \mathrm{CO}_{2} \text { efflux in mass } \\
& \text { - rate of } \mathrm{CO}_{2} \text { mass consumption caused by reaction. }
\end{aligned}
$$

According to Fick's diffusion law, the diffusion is the main transferring behavior for $\mathrm{CO}_{2}$ in concrete. Considering only the diffusion flux generated by the concentration gradient in various directions and ignoring the impact of the flowing of $\mathrm{CO}_{2}$ gas, the rate of $\mathrm{CO}_{2}$ gas influx in mass can be formulated as

$$
M_{\mathrm{IN}}=Q_{\mathrm{CO}_{2} x, x} d y d z+Q_{\mathrm{CO}_{2} y, y} d x d z+Q_{\mathrm{CO}_{2} z, z} d x d y,
$$

where $Q_{\mathrm{CO}_{2} x}, Q_{\mathrm{CO}_{2} y}$ and $Q_{\mathrm{CO}_{2} z}$ are the diffusion fluxes in the $x$-, $y$-, and $z$-axis direction, respectively. Their units are all $\mathrm{kg} \cdot \mathrm{s}^{-1} \cdot \mathrm{m}^{-2} \cdot Q_{\mathrm{CO}_{2} x, x}, Q_{\mathrm{CO}_{2} y, y}$, and $Q_{\mathrm{CO}_{2} z, z}$ are the values of

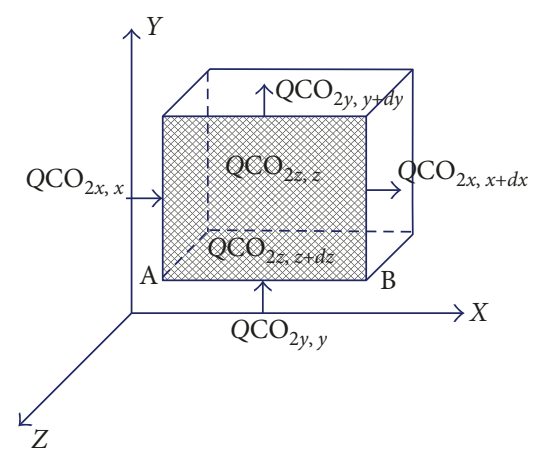

FIgURE 3: Schematic diagram of mass transfer of element on the concrete.

$\mathrm{Q}_{\mathrm{CO}_{2} x}, \mathrm{Q}_{\mathrm{CO}_{2} y}$, and $\mathrm{Q}_{\mathrm{CO}_{2} z}$ in the $x$-, $y$-, and $z$-axis direction, respectively, as shown in Figure 3.

The corresponding quality rate of $\mathrm{CO}_{2}$ gas efflux in mass in the microunit can be expressed as

$$
\begin{aligned}
M_{\mathrm{OUT}}= & Q_{\mathrm{CO}_{2} x, x+d x} d y d z+Q_{\mathrm{CO}_{2} y, y+d y} d x d z \\
& +Q_{\mathrm{CO}_{2} z, z+d z} d x d y .
\end{aligned}
$$

The rate of cumulative $\mathrm{CO}_{2}$ in mass is

$$
M_{\mathrm{L}}=\frac{\partial C_{\mathrm{CO}_{2}}}{\partial t} d x d y d z
$$

where $C_{\mathrm{CO}_{2}}$ is the mass concentration of $\mathrm{CO}_{2}$.

If the rate of $\mathrm{CO}_{2}$ mass consumption per unit volume is $r_{\mathrm{CO}_{2}}$, the rate of $\mathrm{CO}_{2}$ gas mass consumption in the microunit is

$$
M_{\mathrm{H}}=r_{\mathrm{CO}_{2}} d x d y d z \text {. }
$$

Substituting (3)-(5) into (2), the equilibrium equation can be given as

$$
\begin{aligned}
\frac{\partial C_{\mathrm{CO}_{2}}}{\partial t} d x d y d z= & \left(Q_{\mathrm{CO}_{2} x, x} d y d z+Q_{\mathrm{CO}_{2} y, y} d x d z\right. \\
& \left.+Q_{\mathrm{CO}_{2} z, z} d x d y\right)-\left(Q_{\mathrm{CO}_{2} x, x+d x} d y d z\right. \\
& \left.+Q_{\mathrm{CO}_{2} y, y+d y} d x d z+Q_{\mathrm{CO}_{2} z, z+d z} d x d y\right) \\
& -r_{\mathrm{CO}_{2}} d x d y d z .
\end{aligned}
$$

Taking the limit values for $d x, d y$, and $d z$ as being closer to zero, (6) can be expressed as

$$
\frac{\partial C_{\mathrm{CO}_{2}}}{\partial t}=\left(\frac{\partial Q_{\mathrm{CO}_{2} x}}{\partial x}+\frac{\partial Q_{\mathrm{CO}_{2} y}}{\partial y}+\frac{\partial Q_{\mathrm{CO}_{2} z}}{\partial z}\right)-r_{\mathrm{CO}_{2}} .
$$

Assuming the materials in the concrete structure are isotropic, the diffusion fluxes of $\mathrm{CO}_{2}$ in concrete can be calculated by Fick's first law as

$$
Q_{\mathrm{CO}_{2} x}=-D_{A B}(t, T) \frac{d C_{\mathrm{CO}_{2}}}{d x},
$$

where $D_{A B}(t, T)$ is the diffusion coefficient and $d C_{\mathrm{CO}_{2}} / d x$ is the concentration gradient. The minus sign means the diffusion direction is contrary to the concentration gradient. 
The $\mathrm{CO}_{2}$ diffusion process in concrete is unsteady, and its concentration varies with the distance $x$ and the diffusion time $t$. Combining (8) with (7), we get

$$
\frac{\partial C_{\mathrm{CO}_{2}}}{\partial t}=D_{A B}(t, T)\left(\frac{\partial C_{\mathrm{CO}_{2}}^{2}}{\partial x^{2}}+\frac{\partial C_{\mathrm{CO}_{2}}^{2}}{\partial y^{2}}+\frac{\partial C_{\mathrm{CO}_{2}}^{2}}{\partial z^{2}}\right)+r_{\mathrm{CO}_{2}} .
$$

Most existing studies only consider the carbonation value of concrete under a certain apparent diffusion coefficient. In fact, with the development of carbonation and hydration, the porosity of the carbonation region becomes smaller, and the diffusion rate decreases. According to the research results from the Yoon et al. [29] and Jianxin et al. [7], the diffusion coefficient is time and temperature dependent. Therefore, this paper considers the time- and temperature-dependent diffusion coefficient, and the calculation model is

$$
D_{A B}(t, T)=D_{1} t^{-n_{\mathrm{d}}} \exp \left[\frac{E}{R}\left(\frac{1}{293}-\frac{1}{273+\left(\left(\sum_{i=0}^{t} T(t)\right) / t\right)}\right)\right],
$$

where $D_{1}$ is the $\mathrm{CO}_{2}$ diffusion coefficient after a year, $n_{\mathrm{d}}$ is the age of $\mathrm{CO}_{2}$ diffusion coefficient, $E$ is the activation energy during the diffusion progress $(40 \mathrm{~kJ} / \mathrm{mol})$, and $R$ is the gas constant $(0.008134 \mathrm{~kJ} / \mathrm{mol} \cdot \mathrm{K})$.

In practical engineering, the length of concrete structure is generally large. For convenience, the $\mathrm{CO}_{2}$ diffusion problem can be simplified from three-dimensional to twodimensional, which sets $d z=1$ in the control body and only considers diffusion along the $x$ and $y$ directions. When the mass transfer of $\mathrm{CO}_{2}$ gas in concrete is dominated by diffusion, the reaction process ends in the carbonization region, and the rate of $\mathrm{CO}_{2}$ mass consumption is zero $\left(r_{\mathrm{CO}_{2}}=0\right)$. Therefore, (9) can be simplified as

$$
\frac{\partial C_{\mathrm{CO}_{2}}}{\partial t}=D_{A B}(t, T)\left(\frac{\partial C_{\mathrm{CO}_{2}}^{2}}{\partial x^{2}}+\frac{\partial C_{\mathrm{CO}_{2}}^{2}}{\partial y^{2}}\right)=D_{A B}(t, T) \nabla^{2} C_{\mathrm{CO}_{2}}
$$

Equation (11) is the diffusion equation of $\mathrm{CO}_{2}$ gas in concrete, which demonstrates the diffusion law of molecules in the unsteady state. $\nabla$ is the Laplace operator. The solution of this equation is the $\mathrm{CO}_{2}$ concentration function $C_{\mathrm{CO}_{2}}$ at time $t$. The concentration values at any time can be obtained by solving this equation. Finally, the concentration distribution of $\mathrm{CO}_{2}$ gas in the concrete can be obtained. The calculation process can be achieved by using the Matlab program.

\subsection{Finite Element Solution of Diffusion and Mass Transfer} Equations. The main chemical reaction of concrete carbonation is that $\mathrm{CO}_{2}$ penetrates into the pore of concrete and interacts with $\mathrm{CH}, \mathrm{C}_{3} \mathrm{~S}, \mathrm{C}_{2} \mathrm{~S}$, and other basic hydration products produced by the hydration process of cement. Finally, calcium carbonate and other substances are formed.
Following conditions are generally known during the reaction and presented as

(i) Initial condition: when $t=0, C_{\mathrm{CO}_{2}}(0)$ is a certain value.

(ii) Boundary condition: when $x=y=0, C_{\mathrm{CO}_{2}}=C_{\mathrm{CO}_{2}}(0)$ (i.e., the concentration of $\mathrm{CO}_{2}$ is equal to the initial mass concentration). When $x=\alpha$ and $y=\beta$ ( $\alpha$ and $\beta$ tends to infinity), $C_{\mathrm{CO}_{2}}=0$.

(iii) According to Yoon's model [29], the carbonation front equals carbonation depth and the concentration of $\mathrm{CO}_{2}$ is zero at the end of the carbonation depth, and this setting is applied in this paper.

The following differential equation is established considering boundary conditions:

$$
\frac{\partial C_{\mathrm{CO}_{2}}}{\partial t}=D_{A B}(t, T)\left(\frac{\partial C_{\mathrm{CO}_{2}}^{2}}{\partial y^{2}}+\frac{\partial C_{\mathrm{CO}_{2}}^{2}}{\partial y^{2}}\right),
$$

$$
\left.C_{\mathrm{CO}_{2}}(0)\right|_{b}=C
$$

where $b$ is the boundary $(x=0, y=0)$ and $C$ is the constant. This equation is a parabolic partial differential equation.

According to the variation principle and Euler equation, the corresponding function of (12) is

$$
\begin{aligned}
F\left[C_{\mathrm{CO}_{2}}(x, y, t)\right]= & \iint_{D} \frac{D_{A B}(t, T)}{2} \\
& \times\left[\left(\frac{\partial C_{\mathrm{CO}_{2}}}{\partial x}\right)^{2}+\left(\frac{\partial C_{\mathrm{CO}_{2}}}{\partial y}\right)^{2}\right] d x d y \\
& +\iint_{D}\left(\frac{\partial C_{\mathrm{CO}_{2}}}{\partial t}\right) \cdot C_{\mathrm{CO}_{2}} d x d y
\end{aligned}
$$

Hence, solving the partial differential solution (13) can be converted to obtain the extreme value of function $F$ in the carbonation region $D$, and the mass concentration of $C_{\mathrm{CO}_{2}}$ on the boundary $b$ of the region $D$ is known.

According to the function form, the region $D$ is divided into several small triangular meshes, and a typical unit is taken out for analysis, which is the six-node triangular element [30] (Figure 4), and the node $(a, b, c)$ on the edge of the triangular element is located at the middle point of the corresponding edge. Equation (13) can be expressed in the area of the unit as

$$
\begin{aligned}
F_{i}^{\mathrm{e}}\left[C_{\mathrm{CO}_{2}}(x, y, t)\right]= & \iint_{i} \frac{D_{A B}(t, T)}{2} \\
& \cdot\left[\left(\frac{\partial C_{\mathrm{CO}_{2}}}{\partial x}\right)^{2}+\left(\frac{\partial C_{\mathrm{CO}_{2}}}{\partial y}\right)^{2}\right] d x d y \\
& +\iint_{i}\left(\frac{\partial C_{\mathrm{CO}_{2}}}{\partial t}\right) \cdot C_{\mathrm{CO}_{2}} d x d y
\end{aligned}
$$

The mass concentration in the unit $i$ is discretized into a concentration function which is only related to the 


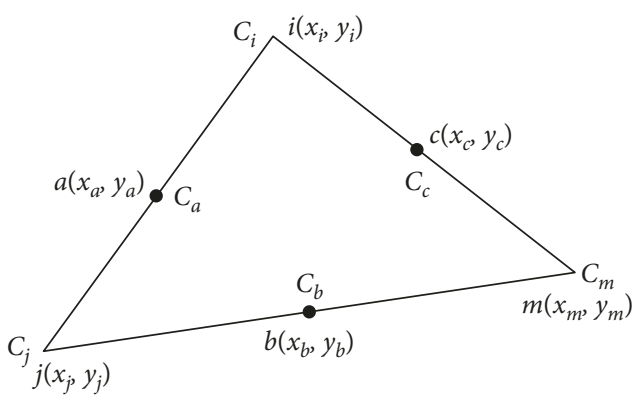

FIgURE 4: Six-node triangle element.

concentration at the node. The column vector of the mass concentration of node is

$$
\{C\}^{\mathrm{e}}=\left[C_{i}, C_{j}, C_{m}, C_{a}, C_{b}, C_{c}\right]^{T} .
$$

A quadratic concentration function of a six-node triangular element is set as

$$
C_{\mathrm{CO}_{2}}=\partial_{1}+\partial_{2} x+\partial_{3} y+\partial_{4} x y+\partial_{5} x^{2}+\partial_{6} y^{2} .
$$

By using the area coordinate $L_{i}(i, j$, and $m)$, the element concentration function can be expressed by shape functions as

$$
C_{\mathrm{CO}_{2}}=N_{i} C_{i}+N_{j} C_{j}+N_{m} C_{m}+N_{a} C_{a}+N_{b} C_{b}+N_{c} C_{c} .
$$

The matrix form of $\mathrm{C}_{\mathrm{CO}_{2}}$ is

$$
C_{\mathrm{CO}_{2}}=\{N\}\{C\}^{\mathrm{e}} .
$$

The elements in the shape function matrix $\{N\}$ can be expressed as

$$
\begin{aligned}
& N_{i}=L_{i}\left(2 L_{i}-1\right), \quad(i, j, m), \\
& N_{a}=4 L_{j} L_{m}, \quad(a, b, c ; i, j, m), \\
& L_{i}=\frac{1}{2 A}\left[\left(x_{j} y_{m}-x_{m} y_{j}\right)+\left(y_{j}-y_{m}\right) x+\left(x_{m}-x_{j}\right) y\right],
\end{aligned}
$$

where $A$ is the area of the triangular element.

Assuming that $\partial C_{\mathrm{CO}_{2}} / \partial t$ is only the function of the position $(x, y)$, the functional variation at a particular time and the variation of time parameter $t$ are considered. The variation calculation of (14) is

$$
\begin{aligned}
\frac{\partial F_{i}^{\mathrm{e}}}{\partial C_{k}}= & D_{A B}(t, T) \iint_{i}\left[\frac{\partial C_{\mathrm{CO}_{2}}}{\partial x} \cdot \frac{\partial^{2} C_{\mathrm{CO}_{2}}}{\partial x \partial C_{k}}+\frac{\partial C_{\mathrm{CO}_{2}}}{\partial y} \cdot \frac{\partial^{2} C_{\mathrm{CO}_{2}}}{\partial y \partial C_{k}}\right] d x d y \\
& +\iint_{i} \frac{\partial C_{\mathrm{CO}_{2}}}{\partial t} \cdot\left(\frac{\partial C_{\mathrm{CO}_{2}}}{\partial C_{k}}\right) d x d y .
\end{aligned}
$$

The derivative of (17) with respect to each mass concentration of node is

$$
\frac{\partial C_{\mathrm{CO}_{2}}}{\partial C_{k}}=N_{k} \quad(k=i, j, m ; a, b, c) .
$$

Considering the unsteady diffusion process of $\mathrm{CO}_{2}$ in the concrete, $C_{k}$ is a function of time parameter $t$. Therefore, we have

$$
\begin{aligned}
\frac{\partial C_{\mathrm{CO}_{2}}}{\partial t}= & {\left[N_{i} N_{j} N_{m} N_{a} N_{b} N_{c}\right] } \\
& \cdot\left[\frac{\partial C_{i}}{\partial t} \frac{\partial C_{j}}{\partial t} \frac{\partial C_{m}}{\partial t} \frac{\partial C_{a}}{\partial t} \frac{\partial C_{b}}{\partial t} \frac{\partial C_{c}}{\partial t}\right] .
\end{aligned}
$$

By combining (20) to (22) and term by term integration of (20), the following equations can be obtained:

$$
\begin{gathered}
\frac{\partial F_{\mathrm{i}}^{\mathrm{e}}}{\partial C_{i}}=D_{A B}(t, T) \sum_{k=i}^{c} h_{i k} C_{k}+\sum_{k=i}^{c} r_{i k} \frac{\partial C_{k}}{\partial t}, \\
\frac{\partial F_{\mathrm{i}}^{\mathrm{e}}}{\partial C_{j}}=D_{A B}(t, T) \sum_{k=i}^{c} h_{j k} C_{k}+\sum_{k=i}^{c} r_{j k} \frac{\partial C_{k}}{\partial t}, \\
\vdots \quad \vdots \\
\frac{\partial F_{\mathrm{i}}^{\mathrm{e}}}{\partial C_{\mathrm{c}}}=D_{A B}(t, T) \sum_{k=i}^{c} h_{c k} C_{k}+\sum_{k=i}^{c} r_{c k} \frac{\partial C_{k}}{\partial t} .
\end{gathered}
$$

It can be obtained from the above equation as

$$
\left\{\frac{\partial F}{\partial C_{\mathrm{CO}_{2}}}\right\}^{\mathrm{e}}=D_{\mathrm{AB}}(t, T)[H]^{\mathrm{e}}\left\{C_{\mathrm{CO}_{2}}\right\}^{\mathrm{e}}+[R]^{\mathrm{e}}\left\{\frac{\partial C_{\mathrm{CO}_{2}}}{\partial t}\right\}^{\mathrm{e}} \text {. }
$$

The coefficient matrices $[H]$ and $[R]$ are calculated as

$$
\begin{aligned}
& h_{i i}=\iint_{i}\left(\frac{\partial N_{i}}{\partial x} \cdot \frac{\partial N_{i}}{\partial x}+\frac{\partial N_{i}}{\partial y} \cdot \frac{\partial N_{i}}{\partial y}\right) d x d y, \\
& h_{i j}=\iint_{i}\left(\frac{\partial N_{i}}{\partial x} \cdot \frac{\partial N_{j}}{\partial x}+\frac{\partial N_{i}}{\partial y} \cdot \frac{\partial N_{j}}{\partial y}\right) d x d y,
\end{aligned}
$$

$$
\begin{aligned}
& \vdots \\
& r_{i i}=\iint_{i}\left(N_{i} \cdot N_{i}\right) d x d y, \\
& r_{i j}=\iint_{i}\left(N_{i} \cdot N_{j}\right) d x d y,
\end{aligned}
$$$$
\vdots
$$

Other factors can be recursive based on the above equations. Based on the forward difference method, the concentration of $\mathrm{CO}_{2}$ can be given as

$$
\frac{\partial C_{\mathrm{CO}_{2}}}{\partial t}=\frac{\left\{C_{\mathrm{CO}_{2}}\right\}_{t+\Delta t}-\left\{C_{\mathrm{CO}_{2}}\right\}_{t}}{\Delta t} .
$$




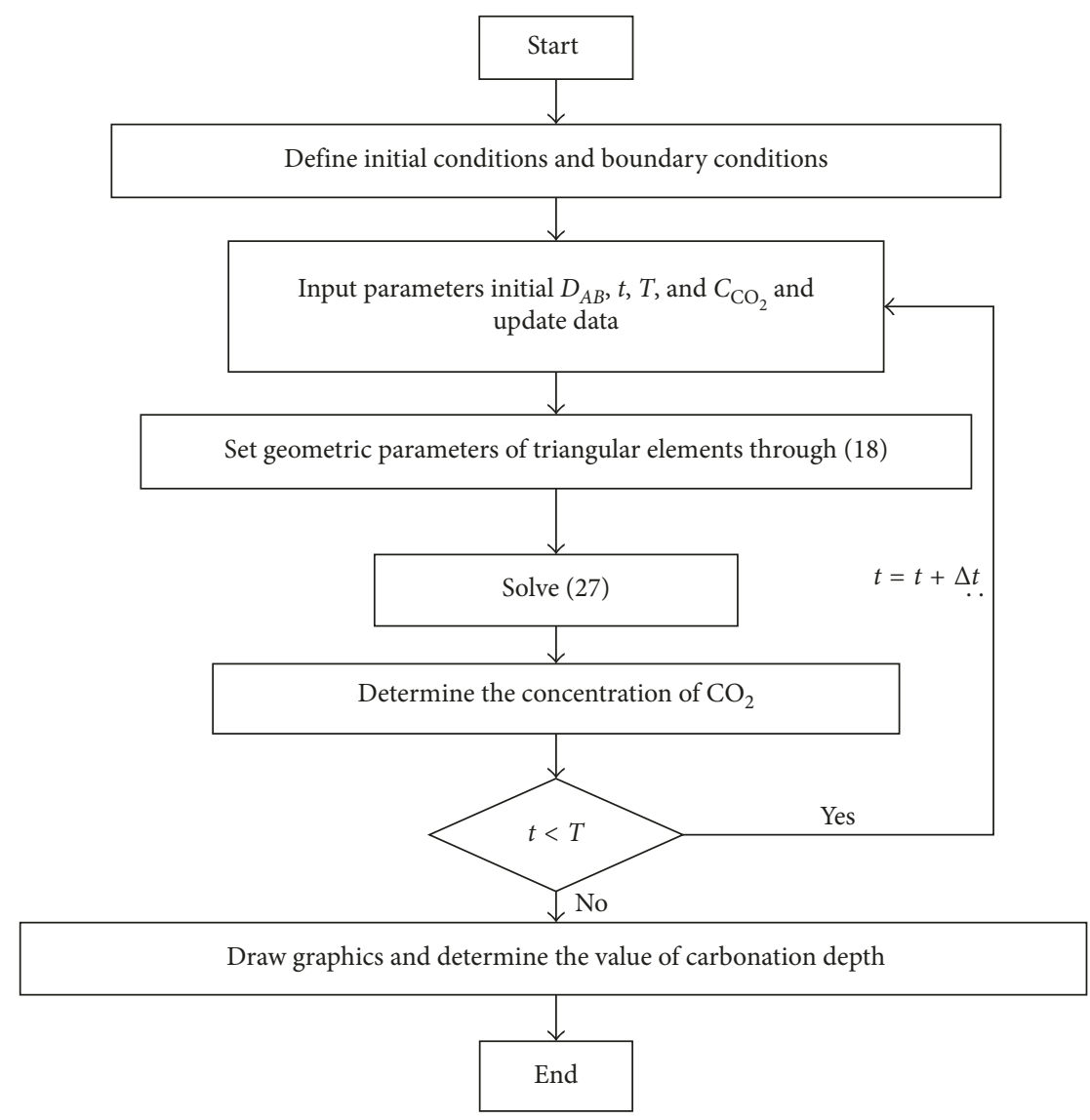

FIGURE 5: Flow chart of the program.

Substituting (26) into (27) gives

$$
\begin{aligned}
\left\{\frac{\partial F}{\partial C_{\mathrm{CO}_{2}}}\right\}^{\mathrm{e}}= & D_{A B}(t, T)[H]^{\mathrm{e}}\left\{C_{\mathrm{CO}_{2}}\right\}^{\mathrm{e}}+\Delta t^{-1}[R]^{\mathrm{e}}\left\{C_{\mathrm{CO}_{2}}\right\}_{t+\Delta t}^{\mathrm{e}} \\
& -\Delta t^{-1}[R]^{\mathrm{e}}\left\{C_{\mathrm{CO}_{2}}\right\}_{t}^{\mathrm{e}} .
\end{aligned}
$$

According to the finite element method, the carbonation area $D$ is discretized into finite triangular elements and $n$ nodes, and the mass concentration of the corresponding elements is distributed to each node. Therefore, it is necessary to solve the concentration values at each node and then solve the mass concentration distribution in the area $D . F_{i}^{\mathrm{e}}$ is the function of triangular elements, and the function of the entire region $D$ is $F=\sum_{i=1}^{n} F_{i}^{\mathrm{e}}$. The function is a multivariate function to express the mass concentration of the unknown nodes. Combining with the variation principle, solving functional extremum can be converted to solve the extremum value of multivariate functions. The extreme condition for the function is

$$
\frac{\partial F}{\partial C_{u}}=\frac{\sum_{i=1}^{n} \partial F_{i}^{\mathrm{e}}}{\partial C_{u}}=0 \quad(u=1,2,3, \ldots) .
$$

The coefficient matrixes are synthesized as $H=\sum H^{\mathrm{e}}$ and $R=\sum R^{\mathrm{e}}$, respectively, and the recursion equation can be obtained by combining (27) as
$D_{A B}(t, T) H\left\{C_{\mathrm{CO}_{2}}\right\}_{t+\Delta t}+\Delta t^{-1} R\left\{C_{\mathrm{CO}_{2}}\right\}_{t+\Delta t}=\Delta t^{-1} R\left\{C_{\mathrm{CO}_{2}}\right\}_{t}$,

where $\left\{\mathrm{C}_{\mathrm{CO}_{2}}\right\}_{t}$ is the initial mass concentration of $\mathrm{CO}_{2}$, and the concentration of the $\mathrm{CO}_{2}$ value at any time interval $(\Delta t)$ can be obtained through setting the initial concentration of $\mathrm{CO}_{2}$ and solving (29).

2.3. Modeling of Carbonation Process. The finite element method is implemented in the Matlab platform, and the flow chart of the program is shown in Figure 5. The carbonation surface of the test specimen is simplified $(75 \mathrm{~mm} \times 75 \mathrm{~mm})$, and a simulation process at a carbonation age is shown in Figure 6. The direction of arrow represents the diffusion direction of $\mathrm{CO}_{2}$ gas after penetrating into the concrete and along the straight line OA (Figure 6). Areas from red to blue represent the transition from the carbonated zone to the partially carbonated zone and to the noncarbonated zone, respectively. The L-shaped curves represent the distribution curve of $\mathrm{CO}_{2}$ concentration in the concrete, and the values of curves are $\mathrm{C}_{\mathrm{CO}_{2}}, 0.9 \mathrm{C}_{\mathrm{CO}_{2}}, \ldots, 0.1 C_{\mathrm{CO}_{2}}$, respectively. Carbonation depth values at the corner and other positions are calculated for comparison, and the carbonation depth values at the corner $\left(X_{j}\right)$ and other positions $\left(X_{q}\right)$ for C25, C30, and $\mathrm{C} 35$ concrete are obtained under the condition of three kinds of $\mathrm{CO}_{2}$ emissions strategy (A1F1, B1, and Best 


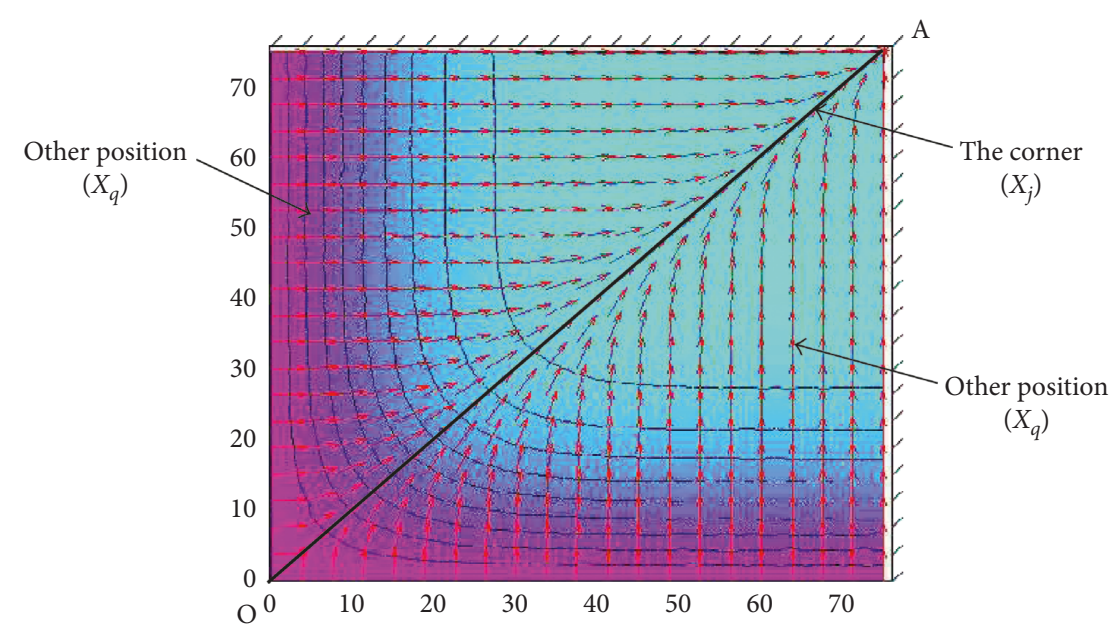

FiguRE 6: Simulation process at the carbonation age.

mitigation) [3] for the next 100 years from 2000 as shown in Figure 7 . The corner refers the line $\mathrm{OA}$, and other positions are the upper triangular and lower triangular positions except the corner. It can be found that the ratio of the carbonation depth value at the corner $\left(X_{j}\right)$ to that at the other positions $\left(X_{q}\right)$ is between 1.3 and 1.4. Therefore, when predicting the carbonation depth of concrete structures, it is necessary to consider the problem of different carbonation depths at different positions.

\section{Experimental Test Programs}

3.1. Material Properties. The sizes of standard concrete blocks in this test were $150 \mathrm{~mm} \times 150 \mathrm{~mm} \times 150 \mathrm{~mm}$. Three different concrete water-cement ratios $(0.65,0.55$, and 0.45$)$ were designed. The designed concrete compressive strengths in this experiment were $25 \mathrm{MPa}, 30 \mathrm{MPa}$, and $35 \mathrm{MPa}$, respectively. The mix compositions for concrete blocks are shown in Table 1 . The blocks were taken out after the 28 days standard curing period and baked for 48 hours at $60 \pm 2^{\circ} \mathrm{C}$ and then put into a closed carbonation chamber (Figure 8). In addition, the test also used 1\% phenolphthalein ethanol solution to determine the carbonation depth.

3.2. Test Instruments. The test was carried out in both the high- and low-temperature carbonation chambers. The $\mathrm{CO}_{2}$ gas supply device (including gas cylinders and pressure gauge) was used to maintain the $\mathrm{CO}_{2}$ concentration in the chamber. The test block was broken by the universal testing machine. The carbonation depths were measured by the digital carbonation depth detector (HC-TH01).

3.3. Test Parameters. Based on the different concrete strengths, water-cement ratio $(w / c)$, temperature, and test time, nine groups of the concrete samples were set up in the test. There were totally fifteen samples in each group that is divided into five subgroups. In each subgroup, three concrete samples were tested for every test time. Table 2 presents the detailed setting of each parameter for each group in the test.
3.4. Test Progress. One side of the block was tested for carbonation, while the remaining five surfaces were protected with epoxy resin, and the space between components was larger than $5 \mathrm{~cm}$ as shown in Figure 8. These samples were placed in a chamber containing $20 \pm 3 \%$ concentration of $\mathrm{CO}_{2}$ at 20 (30 or 40$) \pm 2{ }^{\circ} \mathrm{C}$ and $70 \pm 5 \%$ relative humidity. During the test, the temperature and humidity were measured and recorded every four hours, and the $\mathrm{CO}_{2}$ mass concentration on the surface of the block in the chamber was kept constant. These blocks were taken out after designed time (Table 2) and were broken by a universal testing machine from the center of the uniaxial carbonation surface to measure the carbonation depth. After the test, the ear syringe was used to blow away the ash and slag on the concrete surface, and then the phenolphthalein ethanol solution was dropped on the concrete surface for about 30 seconds. The carbonation depth value of each measurement point whose space was set as $1 \mathrm{~cm}$ on the surface of concrete block was measured by the carbonation depth detector. The detailed carbonation schematic diagram is shown in Figure 9(a), the uniaxial carbonation surface is divided into corner areas $\left(X_{j}\right)$ and other areas except corner areas $\left(X_{q}\right)$ as shown in Figure $9(\mathrm{~b})$.

When the coarse aggregate is just located at the dividing line of a certain measured point, the average carbonation depth of the tested block on the left and right sides of the coarse aggregate is taken as the depth of the point $x_{i}$. The formula for the average carbonation depth of concrete at different ages is calculated as

$$
\bar{x}_{t}=\sum_{i=1}^{n} \frac{x_{i}}{n},
$$

where $\bar{x}_{t}$ is the average carbonation depth of the test blocks after $t$ days and $n$ is the total point numbers on two sides surface.

\section{Test Results and Discussion}

4.1. Influence of Carbonation Position. According to the experimental data, Figure 10 presents the carbonation depth curve in the corner areas $\left(X_{j}\right)$ and other areas $\left(X_{q}\right)$ for 


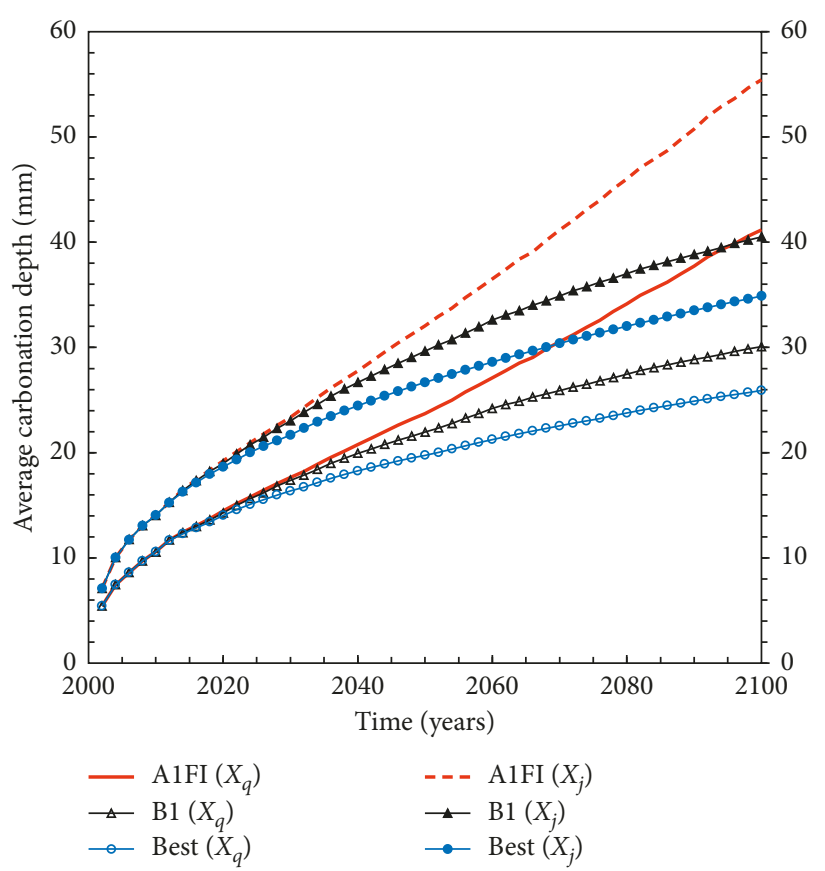

(a)

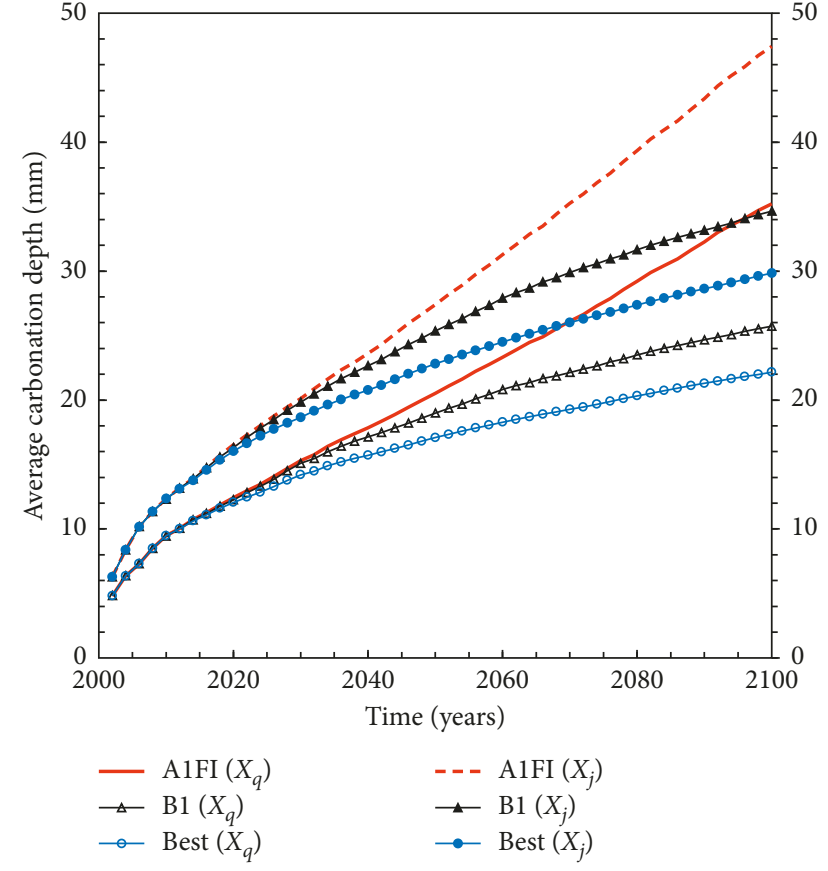

(b)

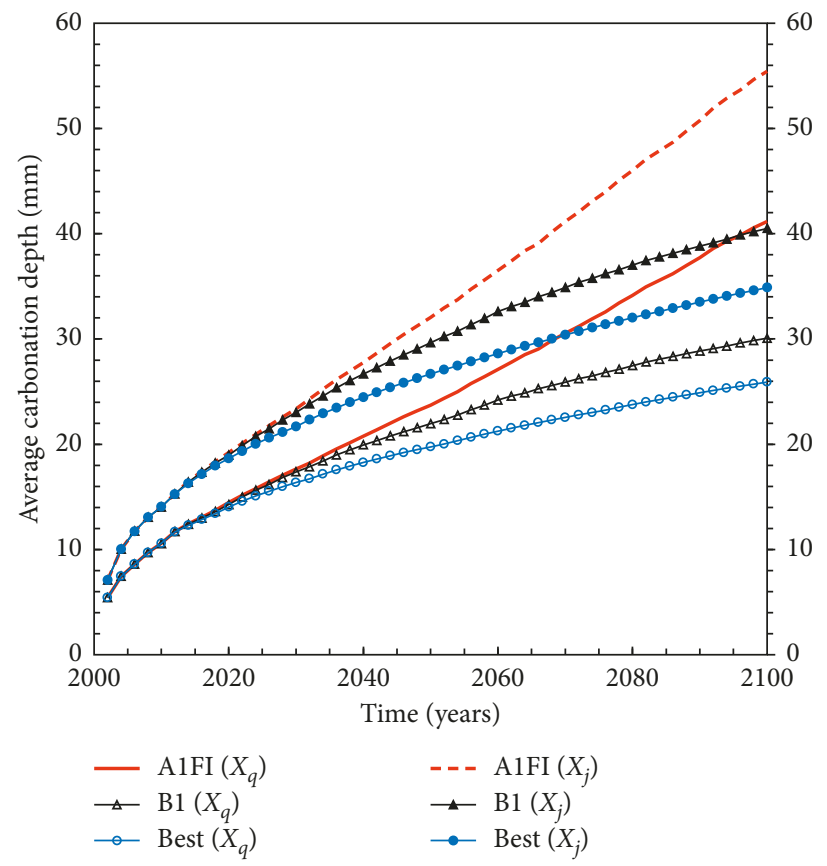

(c)

Figure 7: Carbonation depth: (a) C25 concrete; (b) C30 concrete; (c) C35 concrete.

TABle 1: Mix composition and properties of concrete.

\begin{tabular}{lccccccccc}
\hline $\begin{array}{l}\text { Concrete } \\
\text { grade }\end{array}$ & $\begin{array}{c}\text { Concrete } \\
\text { strength } \\
(\mathrm{MPa})\end{array}$ & $\begin{array}{c}\text { Water- } \\
\text { cement } \\
\text { ratio }(w / \mathrm{c})\end{array}$ & $\begin{array}{c}\text { Cement } \\
\left(\mathrm{kg} / \mathrm{m}^{3}\right)\end{array}$ & $\begin{array}{c}\text { Water } \\
\left(\mathrm{kg} / \mathrm{m}^{3}\right)\end{array}$ & $\begin{array}{c}\text { Sand } \\
\left(\mathrm{kg} / \mathrm{m}^{3}\right)\end{array}$ & $\begin{array}{c}\text { Gravel aggregate } \\
\left(\mathrm{kg} / \mathrm{m}^{3}\right)\end{array}$ & $\begin{array}{c}\text { Fly ash } \\
\left(\mathrm{kg} / \mathrm{m}^{3}\right)\end{array}$ & $\begin{array}{c}\text { Mineral powder } \\
\left(\mathrm{kg} / \mathrm{m}^{3}\right)\end{array}$ & $\begin{array}{c}\text { Admixture } \\
\left(\mathrm{kg} / \mathrm{m}^{3}\right)\end{array}$ \\
\hline C25 & 25 & 0.65 & 230 & 150 & 769 & 1107 & 55 & 59 & 6.5 \\
C30 & 30 & 0.55 & 265 & 147 & 737 & 1105 & 55 & 68 & 7.4 \\
C35 & 35 & 0.45 & 325 & 145 & 680 & 1102 & 55 & 76 \\
\hline
\end{tabular}




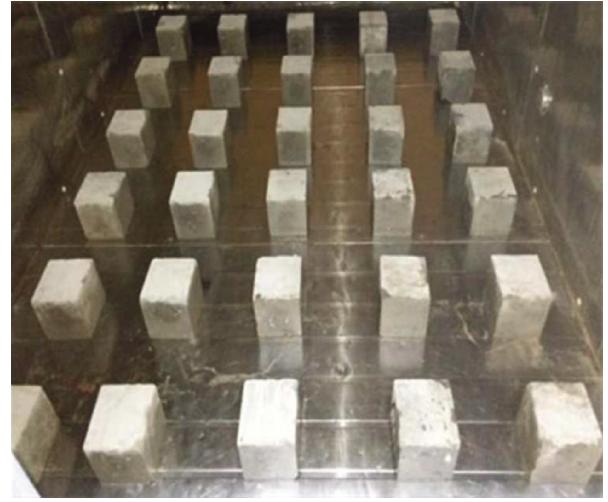

FIGURE 8: Tested block in the carbonation chamber.

TABLE 2: Detailed setting of each parameter for each group.

\begin{tabular}{lcccccrr}
\hline $\begin{array}{l}\text { Group } \\
\text { number }\end{array}$ & $\begin{array}{c}\text { Concrete strength } \\
(\mathrm{MPa})\end{array}$ & $\begin{array}{c}\text { Sample } \\
\text { number }\end{array}$ & $\begin{array}{c}\text { Water-cement } \\
\text { ratio }(w / c)\end{array}$ & $\begin{array}{c}\text { Temperature } \\
\left({ }^{\circ} \mathrm{C}\right)\end{array}$ & $\begin{array}{c}\text { Humidity } \\
(\%)\end{array}$ & $\begin{array}{c}\mathrm{CO}_{2} \text { concentration } \\
(\%)\end{array}$ & \begin{tabular}{c} 
Time $($ days $)$ \\
\hline 1
\end{tabular} \\
\hline 25 & 15 & 0.65 & 20 & 75 & 75 & 20 & $7,14,28,56,84$ \\
2 & 30 & 15 & 0.55 & 20 & 75 & 20 & $7,14,28,56,84$ \\
3 & 35 & 15 & 0.45 & 20 & 75 & 20 & $7,14,28,56,84$ \\
4 & 25 & 15 & 0.65 & 30 & 75 & 20 & $7,14,28,56,84$ \\
5 & 30 & 15 & 0.55 & 30 & 75 & $7,14,28,56,84$ \\
6 & 35 & 15 & 0.45 & 30 & 75 & 20 & $7,14,28,56,84$ \\
7 & 25 & 15 & 0.65 & 40 & 75 & 20 & $7,14,28,56,84$ \\
8 & 30 & 15 & 0.55 & 40 & 75 & 20 & $7,14,28,56,84$ \\
9 & 35 & 15 & 0.45 & 40 & $75,28,56,84$ \\
\hline
\end{tabular}

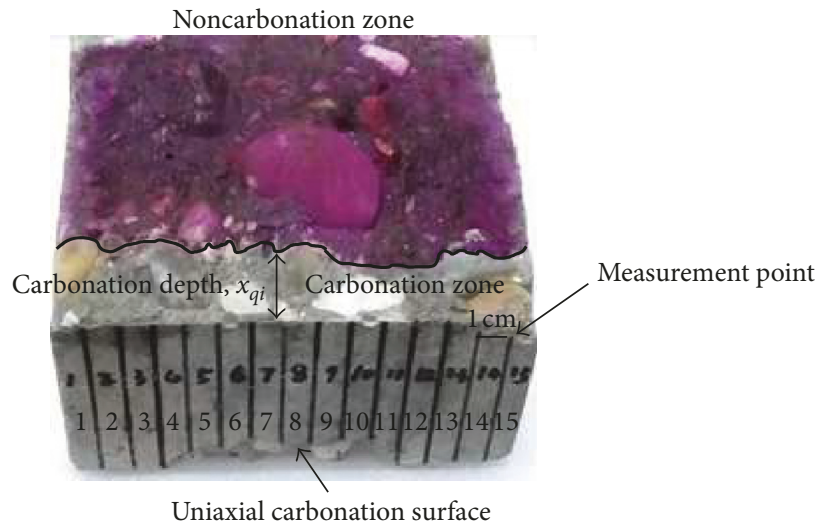

(a)

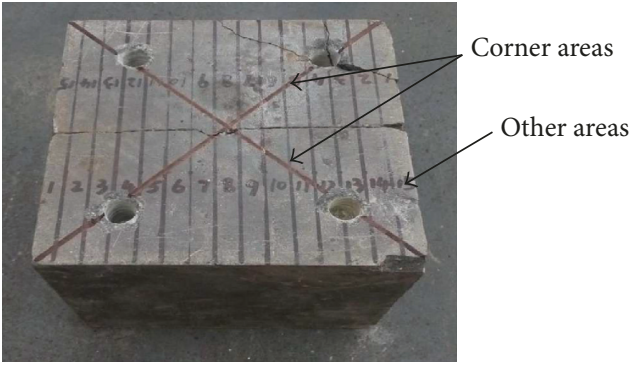

(b)

FIGURE 9: Carbonation schematic diagram: (a) carbonation measurement point and (b) the position of the corner areas and other areas.

concrete with three different water-cement ratios under the conditions of different temperatures. Due to the continuous reaction of the alkaline hydration product and carbon dioxide in the pore of concrete, which generates the difficult soluble substances $\mathrm{CaCO}_{3}$ and blocking gas channel, the carbonation recreation is hindered. This leads to a larger slope for the initial curve, while a smaller slope for the later carbonation depth curve. Under the condition of different water-cement ratios, the carbonation depth of concrete at the corner position is about 1.35 times larger than that at the other positions, which is in good agreement with the finite element results and verifies the correctness of calculation results. The reason of the difference between corner and other area is that the carbonation rate of each direction is different in the closed carbonation chamber, and the corner position is subjected to bidirectional carbonation corrosion on both sides of the corner position.

4.2. Influence of the $w / c$ Ratios. Figure 11 presents the relationship between the carbonation depth and watercement ratio at the age of 28 and 84 days, respectively. Compared with different water-cement ratios of concrete, 


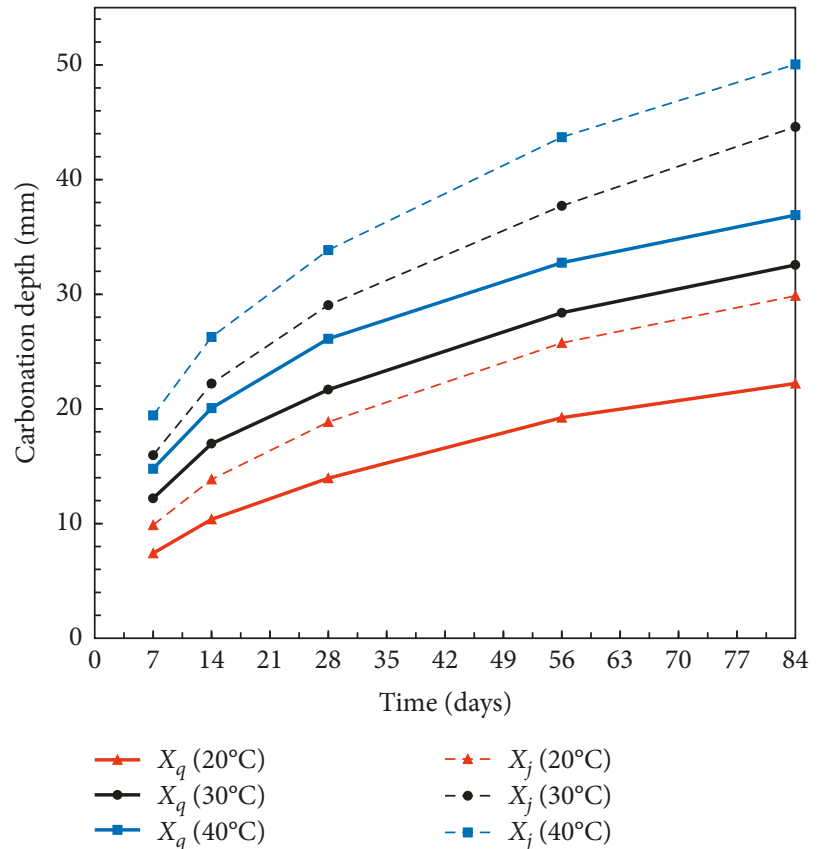

(a)

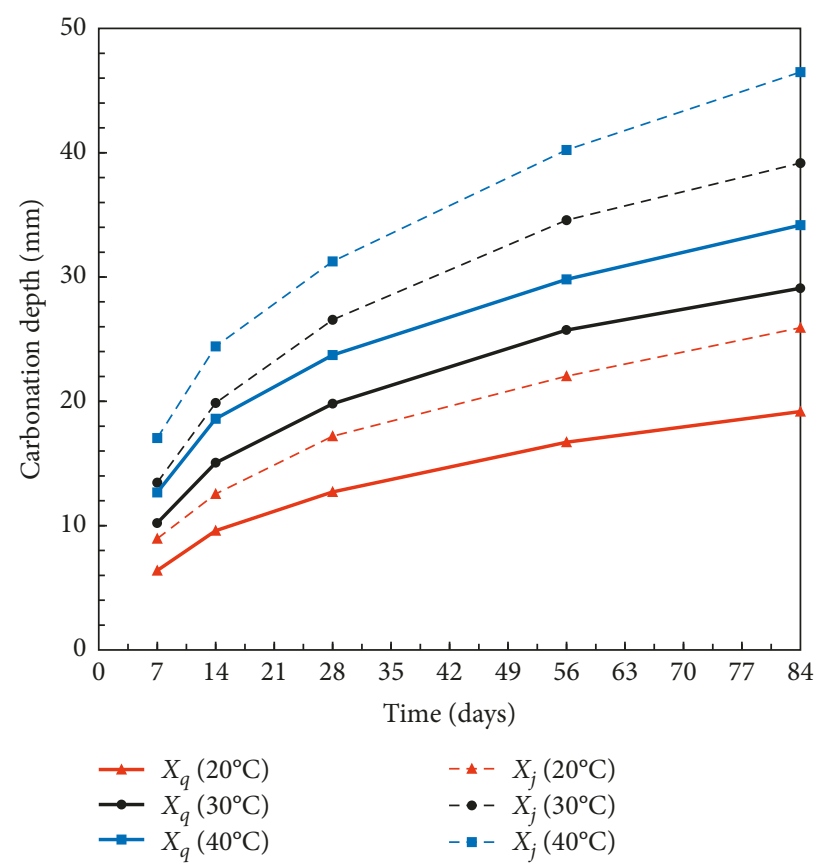

(b)

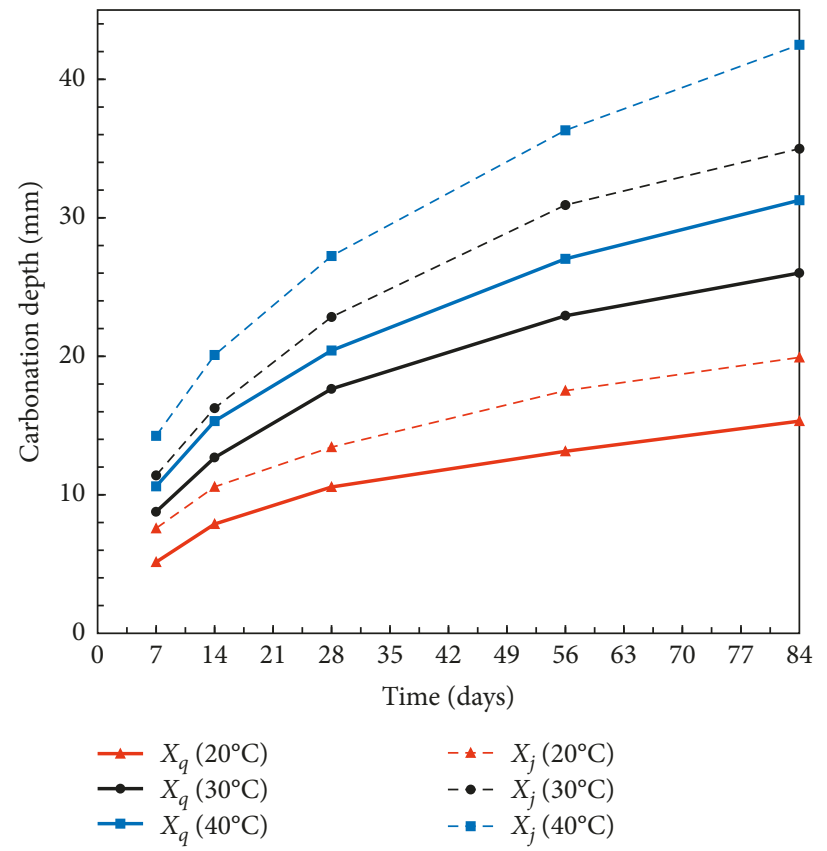

(c)

Figure 10: Carbonation depth curves: (a) C25 concrete $(w / c=0.65)$; (b) C30 concrete $(w / c=0.55)$; (c) C35 concrete $(w / c=0.45)$.

the carbonation depth of C25 concrete is less than that of the rest of the two other kinds of concrete under the same temperature and age. This is because the greater concrete water-cement ratio will result in the greater porosity which leads to the faster carbonation rate. Through the data fitting for the tested result, the relationship between the carbonation rate coefficient $k$ and the water-cement ratio of each group is linear, as shown in Figure 12. This is consistent with the experimental results reported by Jin et al. [31].
4.3. Influence of Temperature. Figure 13 shows the relationship between the carbonation depth and temperature at the ages of 7 and 56 days, respectively. It can be found from Figure 6 that the carbonation rate increases as the temperature increases. Under the condition of the same humidity and $\mathrm{CO}_{2}$ concentration, the carbonation depth would increase about 1.9 times with an increasing temperature from $20^{\circ} \mathrm{C}$ to $40^{\circ} \mathrm{C}$ for the same concrete grade, which is consistent with the data measured by Li et al. [32]. According to the formula of temperature 


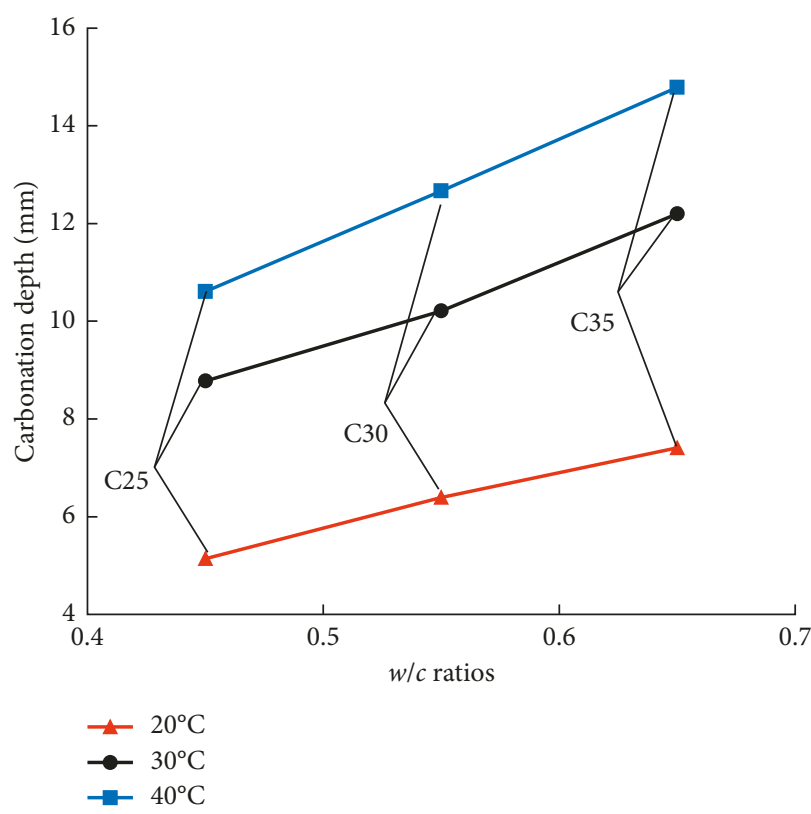

(a)

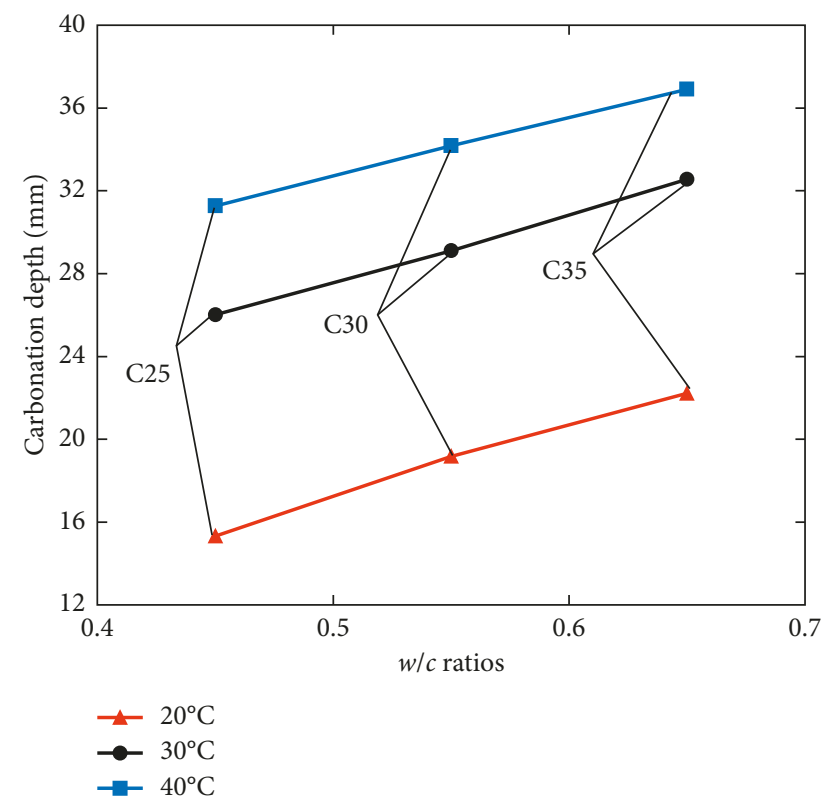

(b)

FIGURE 11: Relationship between water-cement ratio and carbonation depth: (a) carbonation time for 28 days and (b) carbonation time for 84 days.

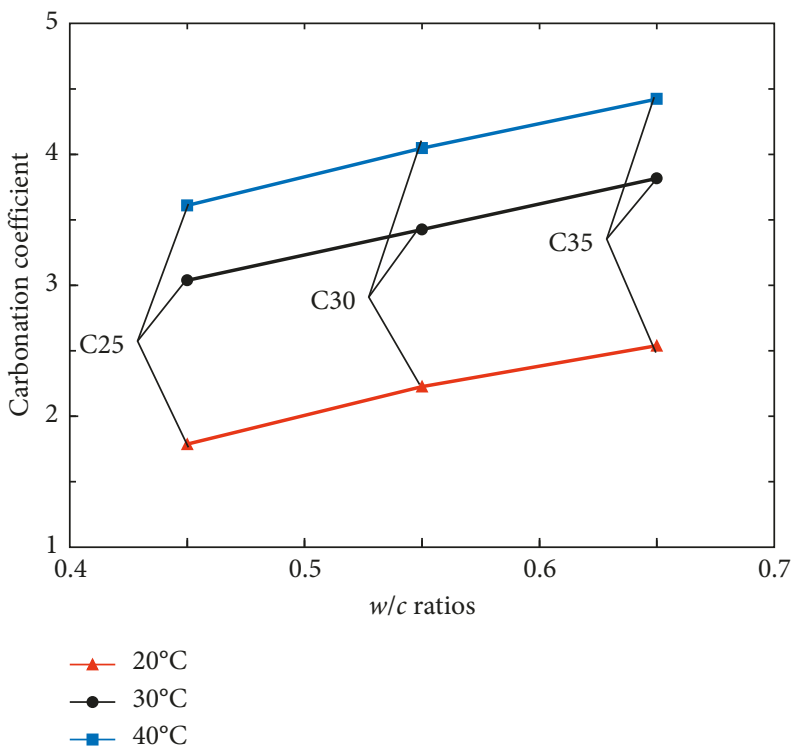

FIGURE 12: Fitting curves of the water-cement ratio and the carbonation rate coefficient.

influence coefficient $\left(k_{T}=e^{(8.748-(2563 / T))}\right)$ proposed by Uomoto and Takada [33], using Origin software to fit the formula $k_{T}=e^{[q((1 / 293)-(1 / T))]}$, the values of fitting coefficient $q$ is given in Table 3 .

It can be observed from Table 3 that the fitting coefficient $q$ is basically consistent for the same concrete whether the carbonation depth is at the corner areas $\left(X_{j}\right)$ or other areas $\left(X_{q}\right)$. The values of the coefficient of carbonation rate for standard specimens at different temperatures can be calculated by the fitting formula, as shown in Table 4.
It can be obtained from Table 4 that the coefficient of carbonation rate is proportional to the ambient temperature. In the range from $10^{\circ} \mathrm{C}$ to $50^{\circ} \mathrm{C}$, the coefficient increases as the temperature increases. The concrete with a smaller water-cement ratio is more sensitive to the temperature.

\section{Comparison and Verification}

The simulation results of concrete carbonation of C25, C30, and C35 three kinds of concrete are compared with that of the tested data, as shown in Figure 13. The tested results are 


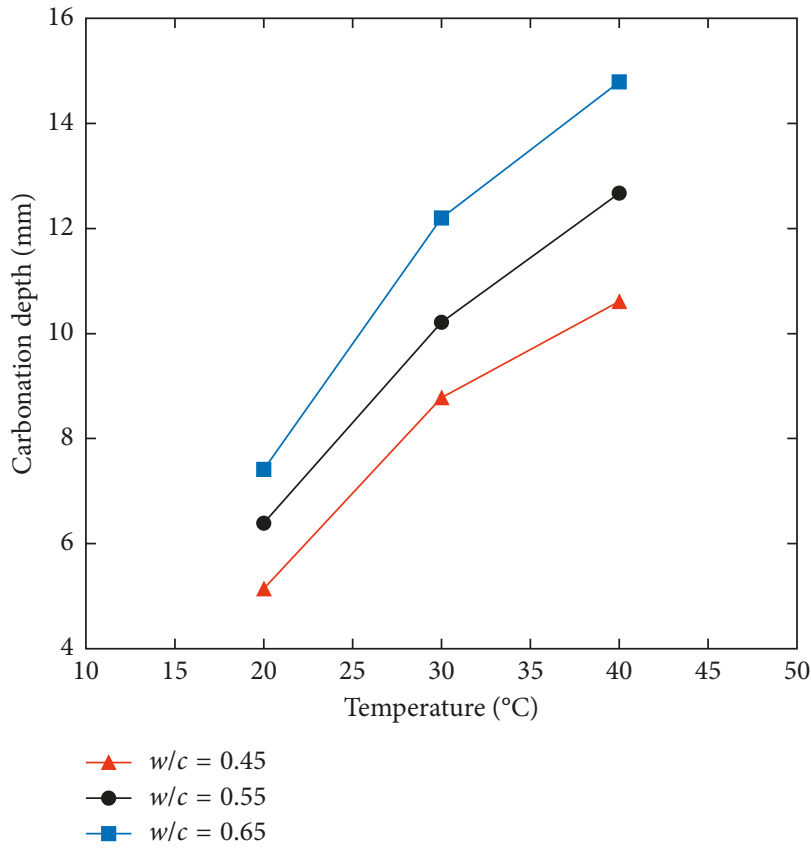

(a)

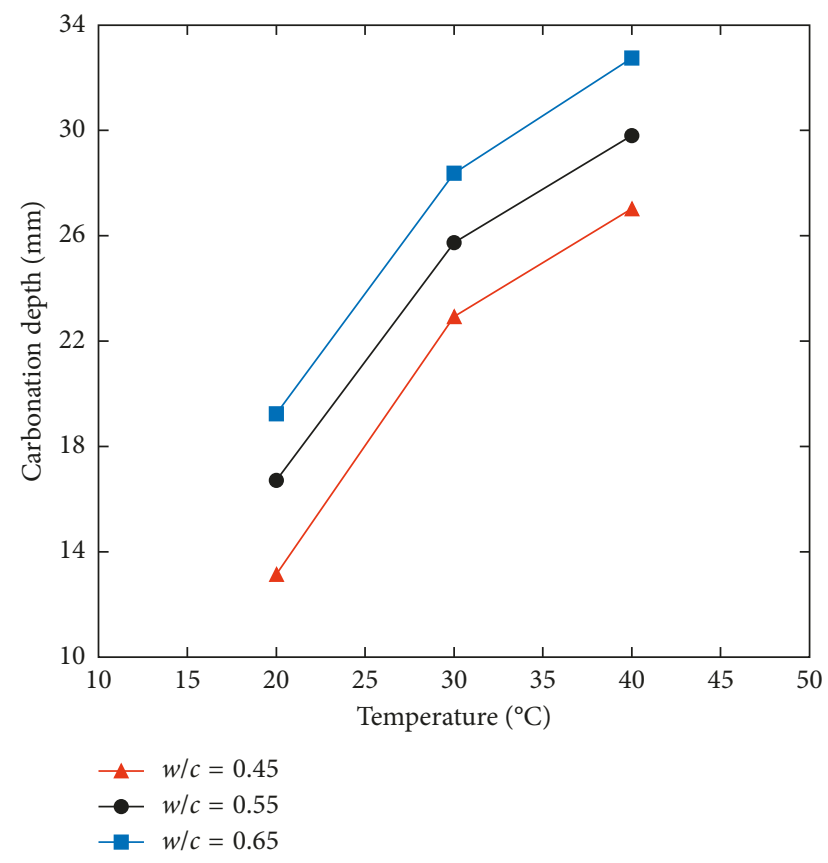

(b)

Figure 13: Curves of temperature and carbonation depth: (a) carbonation time for 7 days and (b) carbonation time for 56 days.

TABLE 3: Results of the values of fitting coefficient $(q)$.

\begin{tabular}{lcccccc}
\hline \multirow{2}{*}{ Fitting formula } & Concrete type & \multicolumn{3}{c}{$\begin{array}{c}\text { Temperature influence } \\
\text { coefficient, } k_{T}\end{array}$} & Fitting results, $q$ & Correlation coefficient, $R^{2}$ \\
\hline & - & $293 \mathrm{~K}$ & $303 \mathrm{~K}$ & $313 \mathrm{~K}$ & - & - \\
& $\mathrm{C} 25\left(X_{q}\right)$ & 1 & 1.5031 & 1.7416 & 2694 & 0.9113 \\
$k_{T}=e^{[q((1 / 293)-(1 / \mathrm{T}))]}$ & $\mathrm{C} 25\left(X_{j}\right)$ & 1 & 1.5062 & 1.7307 & 2672 & 0.9013 \\
& $\mathrm{C} 30\left(X_{q}\right)$ & 1 & 1.5385 & 1.8175 & 2886 & 0.9210 \\
& $\mathrm{C} 30\left(X_{j}\right)$ & 1 & 1.5394 & 1.8245 & 2901 & 0.9237 \\
& $\mathrm{C} 35\left(X_{q}\right)$ & 1 & 1.6998 & 2.0199 & 3409 & 0.8886 \\
& $\mathrm{C} 35\left(X_{j}\right)$ & 1 & 1.7190 & 2.0663 & 3510 & 0.8955 \\
\hline
\end{tabular}

Note. $\mathrm{K}$ is the unit of the absolute temperature.

TABLE 4: Values of $k_{T}$ at different temperatures.

\begin{tabular}{|c|c|c|c|c|c|c|c|c|c|c|}
\hline \multirow{2}{*}{ Reference formula } & \multirow{2}{*}{ Water-cement ratio $(w / c)$} & \multicolumn{9}{|c|}{ Temperature $\left({ }^{\circ} \mathrm{C}\right)$} \\
\hline & & 5 & 10 & 15 & 20 & 25 & 30 & 35 & 40 & 50 \\
\hline$k_{T}=e^{[2683((1 / 293)-(1 / T))]}$ & 0.65 & 0.610 & 0.724 & 0.853 & 1 & 1.166 & 1.353 & 1.562 & 1.795 & 2.341 \\
\hline$k_{T}=e^{[2894((1 / 293)-(1 / T))]}$ & 0.55 & 0.587 & 0.705 & 0.842 & 1 & 1.180 & 1.385 & 1.618 & 1.880 & 2.503 \\
\hline$k_{T}=e^{[3460((1 / 293)-(1 / T))]}$ & 0.45 & 0.529 & 0.659 & 0.815 & 1 & 1.219 & 1.477 & 1.777 & 2.127 & 2.995 \\
\hline
\end{tabular}

also compared with the predicted value $\left(X_{q}\right)$ obtained by Fick's second law, as presented in Figure 14.

Figures 14 and 15 show the carbonation depth value at the corner $\left(X_{j}\right)$ and other positions $\left(X_{q}\right)$, respectively, and the simulation results are basically in good agreement with the tested results. The maximum error is about $5 \%$. This demonstrates that the developed numerical simulation method for predicting carbonation depth in this paper is valid for concrete structures under the atmospheric environment. Moreover, as compared with the predicted results obtained based on Fick's second law, the simulation results of the carbonation depth in this paper are more close to the tested results, which proves the correctness and reliability of the proposed method.

In order to verify the practicability of the finite element model in engineering, some carbonation data under the atmospheric environment from several references are used to compare with the finite element results. The environmental factors are listed in Table 5. The comparison results are shown in Table 6. 


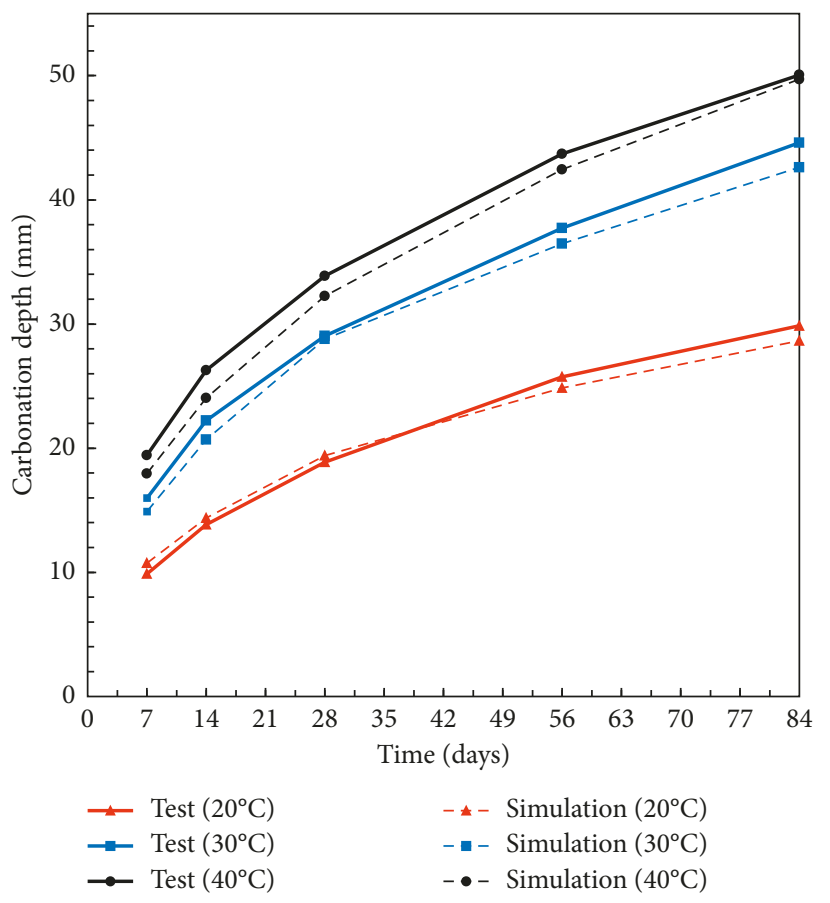

(a)

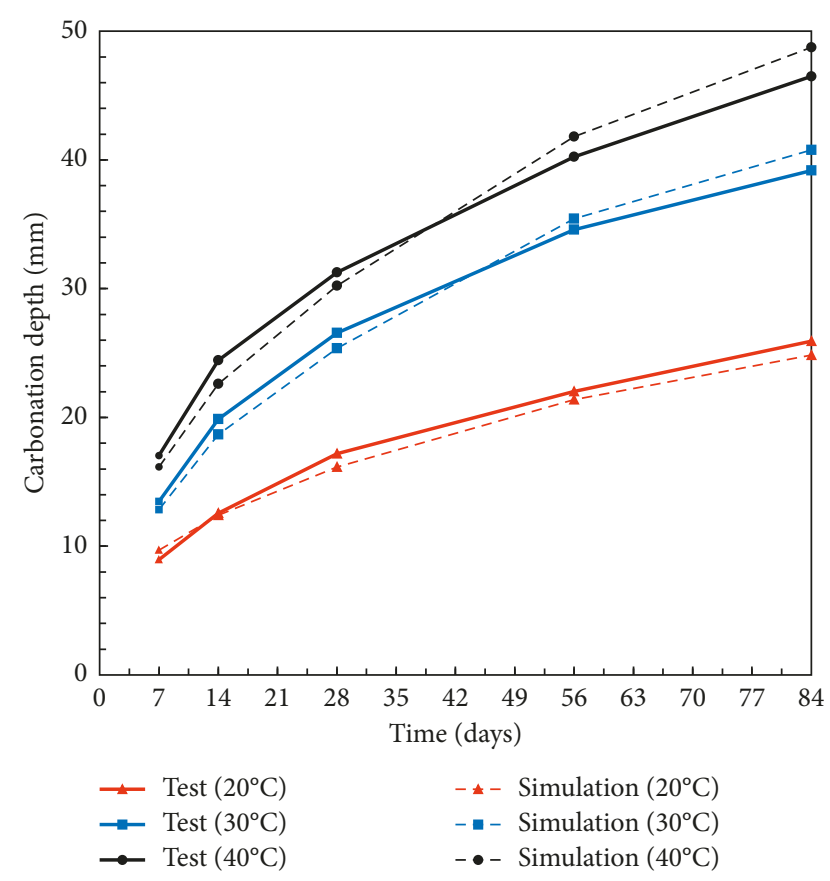

(b)

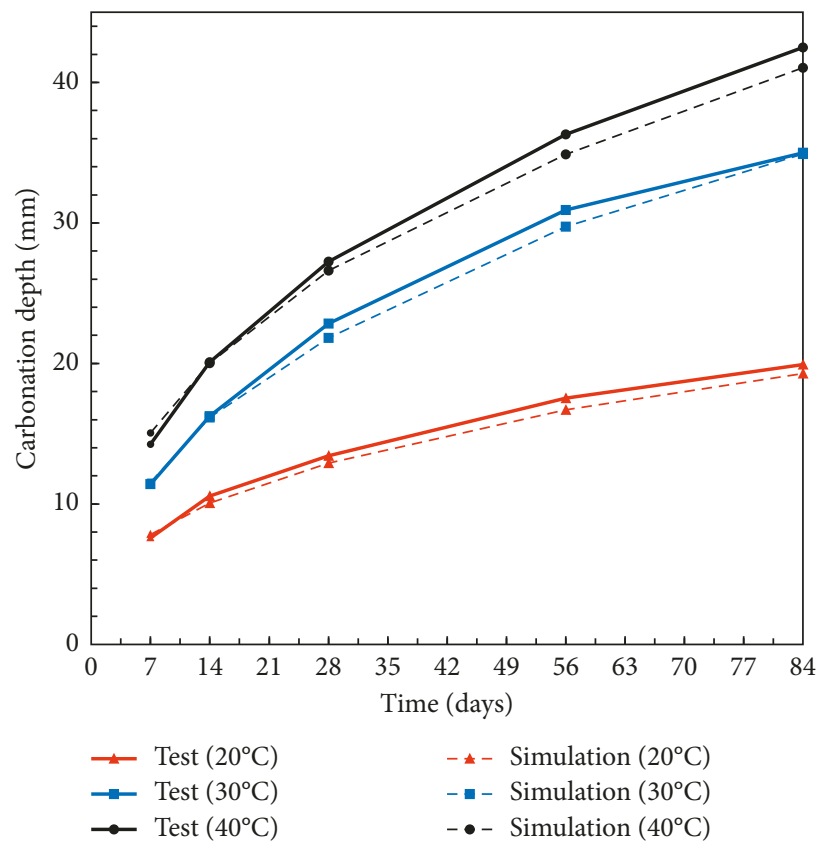

(c)

FIGURE 14: Comparison between test results and simulation results $\left(X_{j}\right)$ at corner: (a) C25 concrete $\left(X_{j}\right)$; (b) C30 concrete $\left(X_{j}\right)$; (c) C35 concrete $\left(X_{j}\right)$. 


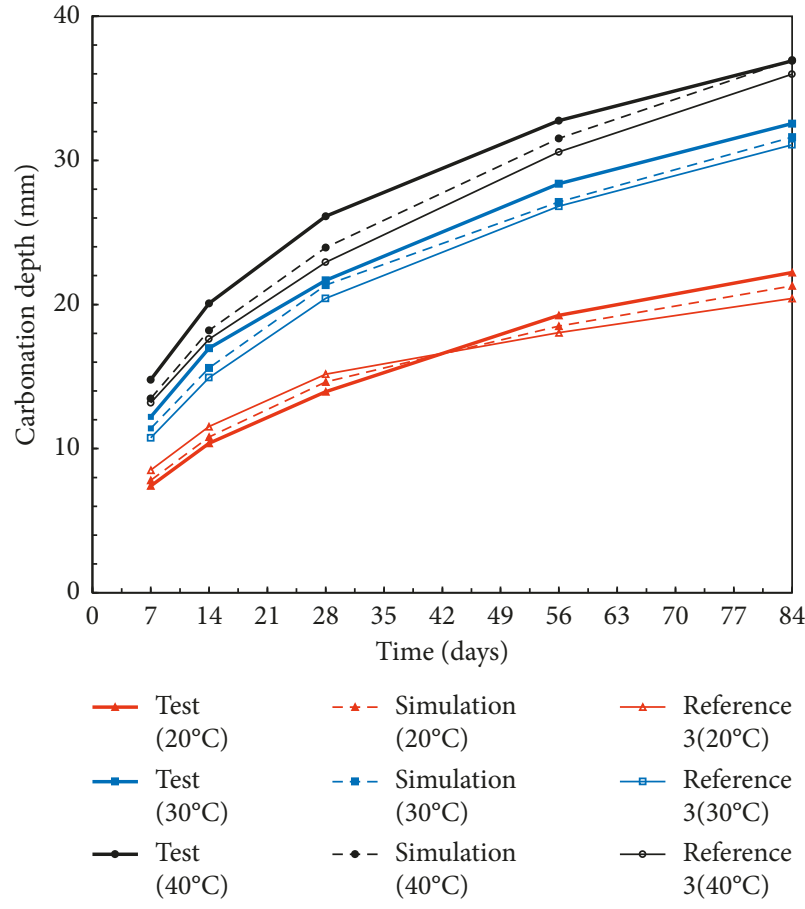

(a)

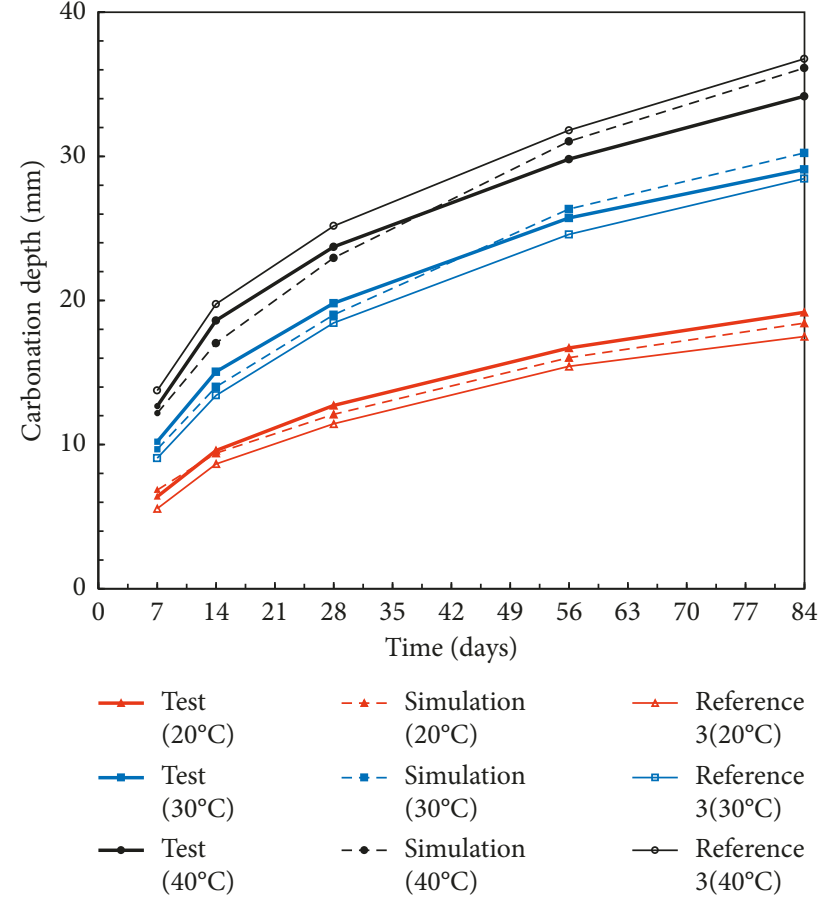

(b)

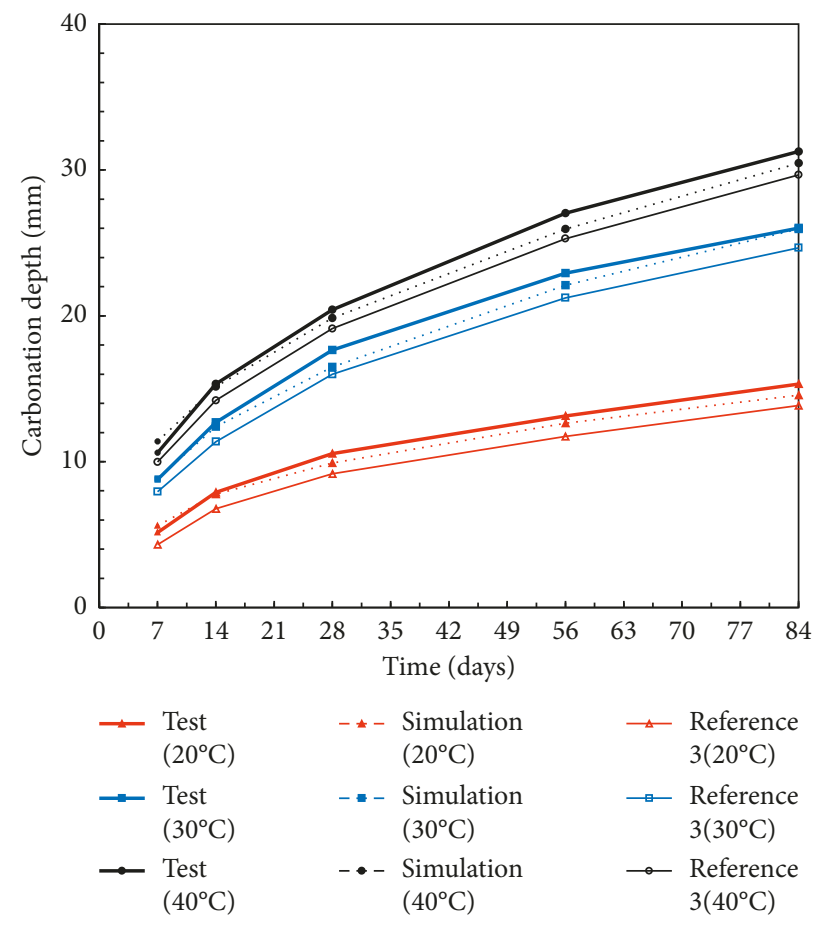

(c)

Figure 15: Comparative test results and simulation results $\left(X_{q}\right)$ at other positions: (a) C25 concrete $\left(X_{q}\right)$; (b) C30 concrete $\left(X_{q}\right)$; (c) C35 concrete $\left(X_{q}\right)$.

TABLE 5: Environmental factors in references.

\begin{tabular}{lccc}
\hline References & Annual average temperature $\left({ }^{\circ} \mathrm{C}\right)$ & Annual average humidity $(\%)$ & $\mathrm{CO}_{2}$ concentration $(\mathrm{ppm})$ \\
\hline$[33,34]$ & 20 & 70 & 340 \\
{$[35]$} & 20 & 70 & 365 \\
{$[36,37]$} & 20 & 70 & 365 \\
\hline
\end{tabular}


TABLE 6: Comparison results between practical engineering and finite element model.

\begin{tabular}{|c|c|c|c|c|c|c|c|}
\hline \multirow[b]{2}{*}{ Reference } & \multirow{2}{*}{$\begin{array}{l}\text { Compressive } \\
\text { strength } \\
\text { of concrete, } f_{\mathrm{cu}} \\
(\mathrm{MPa})\end{array}$} & \multirow[b]{2}{*}{$\begin{array}{c}\text { Age of } \\
\text { carbonation, } \\
t \text { (year) }\end{array}$} & \multicolumn{3}{|c|}{ Carbonation depth } & \multicolumn{2}{|c|}{ Error (\%) } \\
\hline & & & $\begin{array}{c}\text { Practical } \\
\text { measuring } \\
\text { value, } X_{\mathrm{p}} \\
\end{array}$ & $\begin{array}{c}\text { Finite } \\
\text { element } \\
\text { value }\end{array}$ & $\begin{array}{l}\text { Reference } \\
\text { value }\end{array}$ & $\begin{array}{l}\text { Finite element } \\
\text { value }\end{array}$ & $\begin{array}{c}\text { Reference } \\
\text { value }\end{array}$ \\
\hline \multirow{4}{*}[34,35]{} & 28.9 & 1 & 3.10 & 3.20 & 3.37 & 3.2 & 8.7 \\
\hline & 28.9 & 2 & 5.31 & 5.18 & 4.76 & -2.4 & -10.4 \\
\hline & 28.9 & 5 & 7.96 & 7.58 & 7.53 & -4.8 & -5.4 \\
\hline & 28.9 & 10 & 8.75 & 9.73 & 10.66 & 11.2 & 21.8 \\
\hline$[36]$ & 38.0 & 31 & 10.5 & 10.86 & 8.00 & 3.4 & 23.8 \\
\hline \multirow{4}{*}[37,38]{} & 32.87 & 5 & 6.0 & 6.51 & 6.48 & 8.5 & 8.0 \\
\hline & 32.87 & 15 & 9.3 & 10.55 & 10.65 & 13.4 & 14.5 \\
\hline & 32.87 & 25 & 12.7 & 12.69 & 13.66 & 0.0 & 7.6 \\
\hline & 32.87 & 35 & 14.9 & 14.59 & 16.18 & -2.1 & 8.6 \\
\hline
\end{tabular}

It can be found from Table 6 that the error between the finite element value and practical measuring value is from $-4.8 \%$ to $13.4 \%$, and the mean absolute percent error (MAPE) is $5.73 \%$. At the same time, the absolute error of the finite element value is lower than the reference values. In addition, the MAPE between reference values and practical measuring values is $7.67 \%$, which is larger than finite element value. So the finite element model in this paper can more precisely predict the carbonation progress of concrete under the atmospheric environment compared with references.

\section{Conclusions}

This paper firstly builds a 2-D finite element model to predict the carbonation depth considering the time $(t)$ and temperature $(T)$ dependent carbonation coefficients and carbonation position difference for concrete structures. A two-dimensional mass transfer equation on concrete cross section is proposed, which is solved by the finite element method. The time dependence of $\mathrm{CO}_{2}$ mass concentration in different positions of the concrete block is obtained. Secondly, a test program to investigate the diffusion process of $\mathrm{CO}_{2}$ in concrete is carried out. Finally, the simulation results are compared with the tested results. Several conclusions are obtained as follows:

(1) The tested results show that the influence factors such as temperature, time, and water-cement ratio have an obvious effect on the concrete carbonation depth. It was also found from the tested results that under the same humidity and $\mathrm{CO}_{2}$ concentration, the carbonation depth increased about 1.9 times as the environmental temperature increased from $20^{\circ} \mathrm{C}$ to $40^{\circ} \mathrm{C}$.

(2) The carbonation depth curves obtained from the finite element method are consistent with the experimental results and the practical measuring value in engineering. This demonstrates that the numerical method can be applied to predict concrete carbonation of real concrete structures with a satisfactory accuracy.

(3) The tested results and numerical results quantify the ratio of the carbonation depth value at the corner
$\left(X_{j}\right)$ to that at the other positions $\left(X_{q}\right)$, which is from 1.3 to 1.4 . It is necessary to consider the time dependence of $\mathrm{CO}_{2}$ concentration and the concentration differences at different structural positions when predicting the carbonation depth of concrete structures.

\section{Data Availability}

The data used to support the findings of this study are available from the corresponding author upon request.

\section{Conflicts of Interest}

The authors declare that they have no conflicts of interest.

\section{Acknowledgments}

The financial supports of the National Basic Research Program of China (973 Program, Grant no. 2015CB057701), the National Natural Science Foundation of China (Grant no. 51378081), the Natural Science Foundation of Hunan Province (2018JJ2438), and the Natural Science Foundation of Guangdong Province (2015A0310141) are gratefully acknowledged.

\section{References}

[1] R. Engelfried, "Preventive prevention by low permeability coatings," in Proceeding of the Concrete Society Conference on Permeability of Concrete and Its Control, pp. 107-117, London, UK, 1985.

[2] S. Solomon, D. Qin, M. Manning et al., Climate Change 2007: The Physical Science Basis, Cambridge University Press, Cambridge, UK, 2007.

[3] J. Peng, X. Shao, and J. Zhang, "Climate change, $\mathrm{CO}_{2}$ emission scenarios and its effects on carbonation-induced cracking and time-dependent reliability for reinforced concrete structures," China Civil Engineering Journal, vol. 43, no. 6, pp. 74-81, 2010.

[4] J. H. M. Visser, "Influence of the carbon dioxide concentration on the resistance to carbonation of concrete," Construction and Building Materials, vol. 67, pp. 8-13, 2014.

[5] H. Cui, W. Tang, W. Liu, Z. Dong, and F. Xing, "Experimental study on effects of $\mathrm{CO}_{2}$ concentrations on concrete 
carbonation and diffusion mechanisms," Construction and Building Materials, vol. 93, pp. 522-527, 2015.

[6] M. Castellote, L. Fernandez, C. Andrade, and C. Alonso, "Chemical changes and phase analysis of OPC pastes carbonated at different $\mathrm{CO}_{2}$ concentrations," Materials and Structures, vol. 42, no. 4, pp. 515-525, 2009.

[7] P. Jianxin, H. Shouwang, and Z. Jianren, "Corrosion-induced crack performance prediction of RC bridge under chloride attack considering effect of global warming," Engineering Mechanics, vol. 30, no. 8, pp. 103-110, 2013.

[8] W. Wang, C. Lu, Y. Li, G. Yuan, and Q. Li, "Effects of stress and high temperature on the carbonation resistance of fly ash concrete," Construction and Building Materials, vol. 138, pp. 486-495, 2017.

[9] A. Steffens, D. Dinkler, and H. Ahrens, "Modeling carbonation for corrosion risk prediction of concrete structures," Cement and Concrete Research, vol. 32, no. 6, pp. 935-941, 2002.

[10] O. Burkan Isgor and A. G. Razaqpur, "Finite element modeling of coupled heat transfer, moisture transport and carbonation processes in concrete structures," Cement and Concrete Composites, vol. 26, no. 1, pp. 57-73, 2004.

[11] A. V. Saetta and R. V. Vitaliani, "Experimental investigation and numerical modeling of carbonation process in reinforced concrete structures: Part I: theoretical formulation," Cement and Concrete Research, vol. 34, no. 4, pp. 571-579, 2004.

[12] A. V. Saetta and R. V. Vitaliani, "Experimental investigation and numerical modeling of carbonation process in reinforced concrete structures: Part II. Practical applications," Cement and Concrete Research, vol. 35, no. 5, pp. 958-967, 2005.

[13] I. Galan, C. Andrade, and M. Castellote, "Natural and accelerated $\mathrm{CO}_{2}$ binding kinetics in cement paste at different relative humidities," Cement and Concrete Research, vol. 49, pp. 21-28, 2013.

[14] C.-T. Chen and C.-W. Ho, "Influence of cyclic humidity on carbonation of concrete," Journal of Materials in Civil Engineering, vol. 25, no. 12, pp. 1929-1935, 2013.

[15] M. P. Kulakowski, F. M. Pereira, and D. C. C. D. Molin, "Carbonation-induced reinforcement corrosion in silica fume concrete," Construction and Building Materials, vol. 23, no. 3, pp. 1189-1195, 2009.

[16] V. G. Papadakis, "Effect of supplementary cementing materials on concrete resistance against carbonation and chloride ingress," Cement and Concrete Research, vol. 30, no. 2, pp. 291-299, 2000.

[17] K. Sisomphon and L. Franke, "Carbonation rates of concretes containing high volume of pozzolanic materials," Cement and Concrete Research, vol. 37, no. 12, pp. 1647-1653, 2007.

[18] W. Xiao-Yong and P. Ki-Bong, "Analysis of compressive strength development and carbonation depth of high-volume fly ash cement pastes," Materials Journal, vol. 113, no. 2, 2016.

[19] T. de Larrard, B. Bary, E. Adam, and F. Kloss, "Influence of aggregate shapes on drying and carbonation phenomena in 3D concrete numerical samples," Computational Materials Science, vol. 72, pp. 1-14, 2013.

[20] R. V. Silva, R. Neves, J. de Brito, and R. K. Dhir, "Carbonation behaviour of recycled aggregate concrete," Cement and Concrete Composites, vol. 62, pp. 22-32, 2015.

[21] A. Leemann, P. Nygaard, J. Kaufmann, and R. Loser, "Relation between carbonation resistance, mix design and exposure of mortar and concrete," Cement and Concrete Composites, vol. 62, pp. 33-43, 2015.

[22] C.-Q. Lye, R. K. Dhir, and G. S. Ghataora, "Carbonation resistance of fly ash concrete," Magazine of Concrete Research, vol. 67, no. 21, pp. 1150-1178, 2015.
[23] Y. M. Yang, J. X. Peng, J. R. Zhang, and C. S. Cai, “A new method for estimating the scale of fluctuation in reliability assessment of reinforced concrete structures considering spatial variability," Advances in Structural Engineering, 2018.

[24] A. V. Saetta, B. A. Schrefler, and R. V. Vitaliani, "2-D model for carbonation and moisture/heat flow in porous materials," Cement and Concrete Research, vol. 25, no. 8, pp. 1703-1712, 1995.

[25] A. V. Saetta, B. A. Schrefler, and R. V. Vitaliani, "The carbonation of concrete and the mechanism of moisture, heat and carbon dioxide flow through porous materials," Cement and Concrete Research, vol. 23, no. 4, pp. 761-772, 1993.

[26] M. A. Peter, A. Muntean, S. A. Meier, and M. Böhm, "Competition of several carbonation reactions in concrete: a parametric study," Cement and Concrete Research, vol. 38, no. 12 , pp. 1385-1393, 2008.

[27] Q. Wang, J. Wei, R. Dong, and G. Xu, "Numerical analysis of carbonation process for concrete structures," Journal of Wuhan University of Technology, vol. 36, no. 5, pp. 91-96, 2014.

[28] X. Zha, M. Yu, J. Ye, and G. Feng, "Numerical modeling of supercritical carbonation process in cement-based materials," Cement and Concrete Research, vol. 72, pp. 10-20, 2015.

[29] I.-S. Yoon, O. Çopuroğlu, and K.-B. Park, "Effect of global climatic change on carbonation progress of concrete," Atmospheric Environment, vol. 41, no. 34, pp. 7274-7285, 2007.

[30] W. Qu and Y. Zhang, "Finite element analysis about concrete carbonization depth at the section," Journal of Tongji University, vol. 27, no. 4, pp. 412-416, 1999.

[31] J. Jin, G. Wu, J. Weng, C. Wang, Z. Yue, and C. Xu, "Experimental study on influence of cement water ratio on chloride diffusion coefficient and carbonation rate of concrete," Bulletin of the Chinese Ceramic Society, vol. 30, no. 4, pp. 943-949, 2011.

[32] G. Li, Y. Yuan, and O. Geng, "Influences of climate conditions to the concrete carbonization rates," Concrete, vol. 11, pp. 49-53, 2004.

[33] T. Uomoto and Y. Takada, "Factors affecting concrete carbonation ratio," Doboku Gakkai Ronbunshu, vol. 451, pp. 119-128, 1992.

[34] J. Liu, Durability Evaluation of the Concrete Structures, Hunan University, Changsha, China, 2014.

[35] L. Zhang, "Relative research of the natural carbonation and artificial accelerated carbonation of concrete," Journal of Xi'an Institute of Metal and Construction Engineering, vol. 22, no. 3, pp. 207-214, 1990.

[36] D. Niu, Z. Dong, and Y. Pu, "Random model of predicting the carbonated concrete depth," Industrial Construction, vol. 29, no. 9, pp. 41-45, 1999.

[37] B. Sun, G. Liu, and Y. Liu, "Research on the grey forecasting model for concrete carbonation," Journal of Building Materials, vol. 15, no. 1, pp. 42-47, 2012.

[38] Q. Yuan and G. Zhao, "Study on forecast model of time series analysis of concrete carbonization depth," Journal of Dalian University of Technology, vol. 40, no. 3, pp. 344-347, 2000. 


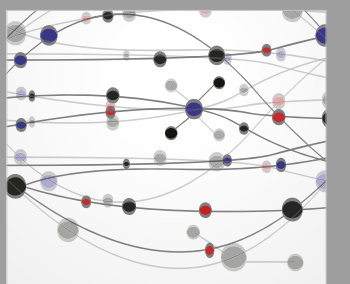

The Scientific World Journal
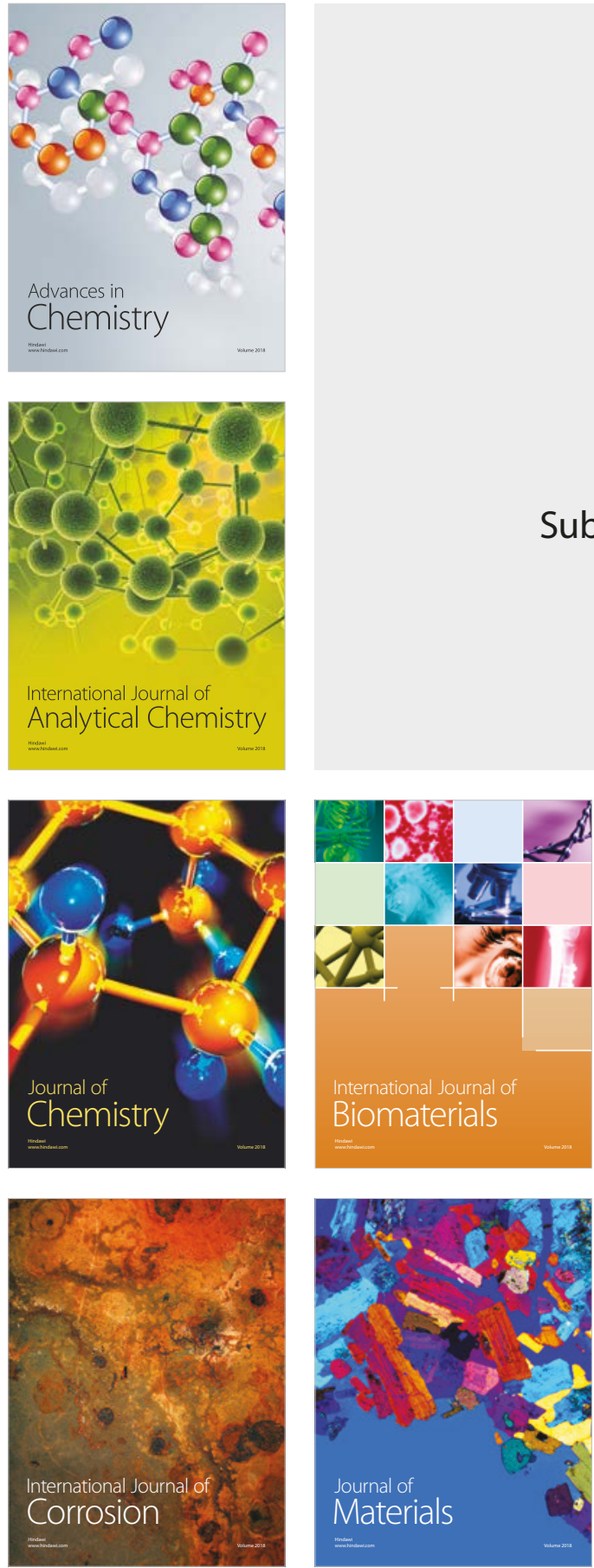

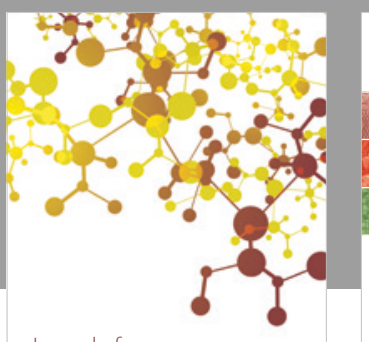

Journal of

Applied Chemistry
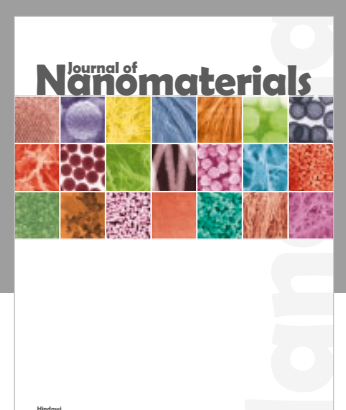

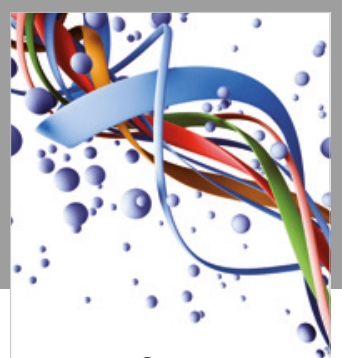

Scientifica

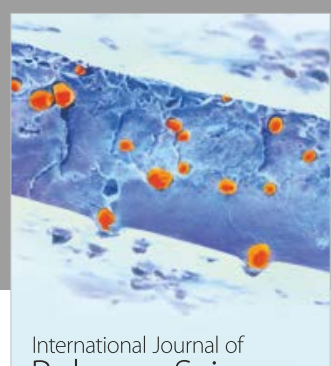

Polymer Science

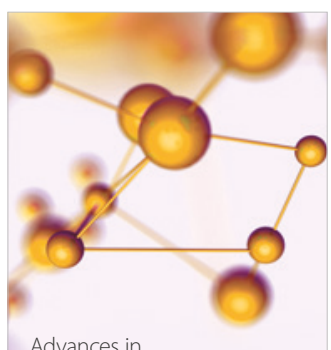

Physical Chemistry
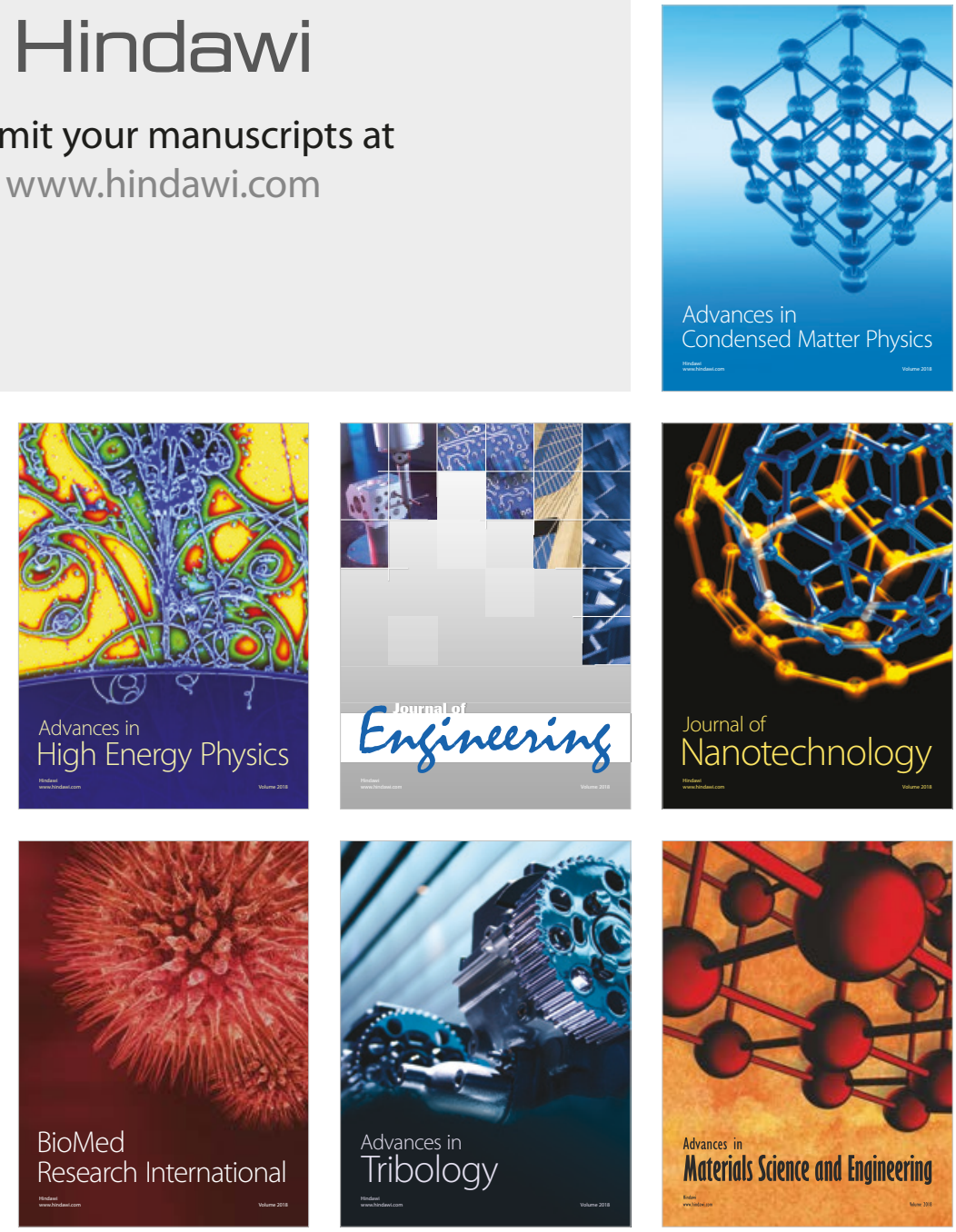